\title{
Safety and Homing of Human Dental Pulp Stromal Cells in Head and Neck Cancer
}

\author{
Greet Merckx $^{1} \cdot$ Melissa Lo Monaco ${ }^{1,2} \cdot$ Ivo Lambrichts $^{1} \cdot$ Uwe Himmelreich $^{3} \cdot$ Annelies Bronckaers $^{1}$ (D) $\cdot$ Esther Wolfs $^{1}$
}

Accepted: 21 March 2021

(C) The Author(s), under exclusive licence to Springer Science+Business Media, LLC, part of Springer Nature 2021

\begin{abstract}
Background Head and neck cancer (HNC) is one of the most common cancers, associated with a huge mortality and morbidity. In order to improve patient outcomes, more efficient and targeted therapies are essential. Bone marrow-derived mesenchymal stromal cells (BM-MSCs) express tumour homing capacity, which could be exploited to target anti-cancer drug delivery to the tumour region and reduce adverse side-effects. Nevertheless, dental pulp stromal cells (DPSCs), an MSC-like population present in teeth, could offer important clinical benefits because of their easy isolation and superior proliferation compared to BM-MSCs. Therefore, we aimed to elucidate the tumour homing and safe usage of DPSCs to treat HNC.

Methods The in vivo survival as well as the effect of intratumourally administered DPSCs on tumour aggressiveness was tested in a HNC xenograft mouse model by using bioluminescence imaging (BLI), (immuno)histology and qRT-PCR. Furthermore, the in vitro and in vivo tumour homing capacity of DPSCs towards a HNC cell line were evaluated by a transwell migration assay and BLI, respectively.

Results Intratumourally injected DPSCs survived for at least two weeks in the tumour micro-environment and had no significant influence on tumour morphology, growth, angiogenesis and epithelial-to-mesenchymal transition. In addition, DPSCs migrated towards tumour cells in vitro, which could not be confirmed after their in vivo intravenous, intraperitoneal or peritumoural injection under the tested experimental conditions.

Conclusions Our research suggests that intratumourally delivered DPSCs might be used as safe factories for the continuous delivery of anti-cancer drugs in HNC. Nevertheless, further optimization as well as efficacy studies are necessary to understand and improve in vivo tumour homing and determine the optimal experimental set-up of stem cell-based cancer therapies, including dosing and timing.
\end{abstract}

Keywords Human dental pulp stromal cells $\cdot$ Head and neck cancer $\cdot$ Tumour homing $\cdot$ Angiogenesis $\cdot$ Epithelial-to-mesenchymal transition $\cdot$ Cell survival $\cdot$ Xenograft mouse model

Annelies Bronckaers and Esther Wolfs contributed equally to this work.

Annelies Bronckaers

annelies.bronckaers@uhasselt.be

1 Faculty of Medicine and Life Sciences, Biomedical Research Institute (BIOMED), Group of Cardio \& Organ Systems (COS), UHasselt - Hasselt University, Agoralaan,

3590 Diepenbeek, Belgium

2 Faculty of Sciences, Department of Veterinary Medicine, Integrated Veterinary Research Unit-Namur Research Institute for Life Science (IVRU-NARILIS), UNamur - University of Namur, Rue de Bruxelles, 5000 Namur, Belgium

3 Department of Imaging and Pathology, Biomedical MRI Unit/MoSAIC, KU Leuven, Herestraat, 3000 Leuven, Belgium

\section{Background}

Head and neck cancer (HNC) is the eighth most common cancer type worldwide with a yearly incidence rate of 835,000 cases [1]. HNC is a generic term for all cancers originating from the upper aerodigestive tract, including the nasal and oral cavity, pharynx and larynx [2]. The most prominent histological subtype (>90\% of all HNC types) is head and neck squamous cell carcinoma (HNSCC), derived from the squamous mucosa cells in the upper aerodigestive tract [3]. Incidence of HNC strongly depends on country, age, gender and cancer subtype [4], which is related to different exposure to associated risk factors, including smoking [5], alcohol [6] and Human Papilloma Virus (HPV) infections [7]. The classical therapeutic strategies of surgery, 
chemotherapy, radiotherapy or a combination are associated with a low survival rate of only $33-63 \%$ after five years, depending on the tumour site [8]. In addition, high morbidity is induced by complications of these therapies, such as disturbed aesthetics, sensory deficits and functional problems with eating and speech, since tumours are located on difficult attainable and important organs [9].

HNSCC used to be divided into two genetic subclasses (HPV-positive or -negative tumours), but more recently, new types and subtypes were described based on histology and molecular characteristics [10]. Due to inhibition of the p53 and retinoblastoma (RB) pathways, cell cycle regulations are severely perturbed in HNSCC. In addition, a subgroup of HNSCC becomes independent of certain growth factors in the epidermal growth factor receptor (EGFR) pathway. Furthermore, mostly all HSCC succeed in escaping the transforming growth factor- $\beta$ (TGF $\beta$ ) pathway, which is responsible for the inhibition of growth. Genetic alterations also lead to frequent activations of the 'phosphoinositide-3-kinase' $(\mathrm{PI} 3 \mathrm{~K}) /$ 'phosphatase and tensin homolog' (PTEN)/Akt pathway in HNSCC $[10,11]$. These findings emphasize the heterogeneity of HNSCC and the associated difficulties in prognosis and therapy. Therefore, alternative targeted therapies, less dependent on the HNSCC subtype, with less adverse side-effects and better functional outcomes are essential to treat HNC. A promising strategy is the use of mesenchymal stromal cells (MSCs) as therapeutic vehicles for the delivery of anti-tumour drugs or therapeutic genes. These stem cells express a specific in vitro and in vivo tropism towards injury and tumour sites under the influence of secreted chemotactic mediators, including stromal cell-derived factor-1 (SDF-1) [12-18]. Reciprocal communication between tumour cells and MSCs is mediated by paracrine extracellular vesicles (EVs), growth factors, cytokines and chemokines, and direct cell-cell contact [19]. The resulting effect of this bidirectional interaction on tumour growth and aggressiveness is controversial $[20,21]$. Some studies indicate that MSCs promote tumour progression by immunosuppression and stimulation of cell survival, proliferation, angiogenesis, epithelial-tomesenchymal transition (EMT), invasion and metastasis [22-27]. In contrast, a tumour-suppressing capacity has been ascribed to MSCs via the inhibition of angiogenesis, tumour growth, invasion and metastasis, and via exerting proinflammatory effects [28-33]. These effects are mediated directly via differentiation of MSCs into malignant cells, cancerassociated fibroblasts and vascular-related cells or indirectly by (paracrine) interaction with immune cells, cancer stem cells, endothelial cells and tumour cells [34]. For example, in vitro co-culture of human palatine tonsil-derived MSCs with hypopharyngeal or laryngeal squamous carcinoma cell lines inhibited cell growth, induced cell cycle arrest in the $\mathrm{G}_{0} /$ $\mathrm{G}_{1}$ phase and apoptosis of the tumour cells in a dose- dependent way $[35,36]$. Similar results were observed for human bone marrow-derived MSC conditioned medium (hBM-MSC CM) with an in vitro decrease in FaDu cell proliferation, survival, EMT marker expression, migration and invasion, at least partially via the paracrine effects of CD109 [36]. In contrast, Scherzad et al. and Liu et al. demonstrated paracrine stimulating effects of hBM-MSCs on in vitro and in vivo proliferation, viability, EMT, migration and metastasis of different HNC cell lines by interleukin-6 (IL-6) secretion and PI3K/Akt signalling [37, 38]. Moreover, in vitro 3D coculture spheroids of human BM-MSCs or adipose tissuederived MSCs (AT-MSCs) and HNSCC cells stimulated tumour migration and invasion via increased matrix metalloproteinase (MMP), IL-8 and VEGF expression [39, 40].

While these in vitro and in vivo migration and safety data were mainly obtained on BM-MSCs, these multipotent stem cells can be isolated from various other tissue sources, including adipose tissue [41, 42], umbilical cord [43] and dental soft tissues [44]. Comparative studies showed significant differences in tumour homing capacity, depending on MSC origin, with a slower and more limited potency for BM-MSCs [45]. Moreover, their invasive isolation and restricted proliferation capacity complicate their clinical use compared to other MSC types [46]. Dental pulp stromal cells (DPSCs), an MSC subtype present in the tooth pulp, have been suggested as a beneficial alternative [47, 48]. DPSCs are embryonically derived from the neural crest and reside in the perivascular niche of the pulp where they play an important role during tooth development and repair. Such as MSCs, they can differentiate into osteocytes, chondrocytes and adipocytes [44]. In addition, in vitro differentiation towards neuron-like cells $[48,49]$, endothelial cells $[50,51]$ and Schwann cells [52] has been described. However, the most important beneficial effects of DPSCs are their paracrine actions, since angiogenic, antiapoptotic and neurotrophic factors are abundantly present in their secretome [53]. In concordance with these findings, they have been successfully applied in various preclinical models such as myocardial infarction, ischemic stroke and peripheral nerve injuries [54-57]. As immunomodulatory properties have been attributed to DPSCs as well, they represent a valuable cell source for clinical applications [58, 59]. Nevertheless, studies on their tumour homing capacity and tumour-promoting or -suppressing effects are currently restricted.

Therefore, the aim of this study was to elucidate whether DPSCs can be used as vehicles for targeted delivery of anticancer therapies in a safe way to treat HNSCC. The impact of DPSCs on tumour growth, angiogenesis, EMT and stem cell survival was monitored in vivo over time in mice HNSCC xenografts using bioluminescence imaging (BLI), quantitative reverse transcriptase polymerase chain reaction (qRT-PCR) and (immuno)histology. Furthermore, in vitro tropism of DPSCs towards the HNSCC FaDu cell line was assessed in 
a transwell migration assay, while in vivo biodistribution was studied in a HNSCC mouse model by BLI. To our knowledge, this is the first study that evaluated both in vivo safety and homing capacity of DPSCs in HNC.

\section{Methods}

\section{Cell Isolation and Culture}

Human DPSCs (hDPSCs) were isolated from dental pulp tissue derived from wisdom teeth of healthy donors $(n=14$, age $17 \pm 0.47$ years, both sexes) undergoing tooth extraction for orthodontic or therapeutic reasons in Ziekenhuis OostLimburg (ZOL, Genk, Belgium). The explant outgrowth isolation method was applied as previously described [60]. Briefly, the teeth were disinfected with $100 \%$ ethanol, and mechanically fractured after which the dental pulp could be gently removed. Next, pulp tissue was rinsed in cell culture medium, consisting of alpha modified Minimum Essential Medium ( $\alpha$-MEM, Sigma-Aldrich, St-Louis, MO, USA), enriched with $10 \%$ heat-inactivated foetal bovine serum (FBS, Biowest, Nuaillé, France), 2 mM L-glutamine, $100 \mathrm{U} /$ $\mathrm{mL}$ penicillin and $100 \mu \mathrm{g} / \mathrm{mL}$ streptomycin (Sigma-Aldrich). The tissue was minced into fragments of $1-2 \mathrm{~mm}^{3}$, placed in 6-well plates and maintained at $37{ }^{\circ} \mathrm{C}$ in a humidified atmosphere containing $5 \% \mathrm{CO}_{2}$. Every 2-3 days, culture medium was refreshed and when reaching 70-80\% confluence, cells were passaged by using $0.05 \%$ Trypsin/EDTA (SigmaAldrich). In compliance with the International Society for Cell \& Gene Therapy (ISCT) guidelines [61], resulting cells could differentiate into osteocytes osteoblasts, chondrocytes and adipocytes and expressed a MSC marker profile. Immunophenotyping was performed by flow cytometry and showed the presence of MSC markers CD29, CD44, CD73, CD90 and CD105, while endothelial and haematopoietic markers CD31, CD34, CD45 and CD117 were absent [60, 62]. Pooled DPSCs of three donors were transduced with a lentiviral vector encoding Firefly luciferase (Fluc), enhanced green fluorescent protein (eGFP) and a blasticidin resistance cassette. After transduction, stably expressing cells were selected with blasticidin $(10 \mu \mathrm{g} / \mathrm{mL}$, InvivoGen, Toulouse, France). Stem cells were used until passage 15.

The FaDu tumour cell line, a human HNSCC cell line of the hypopharynx, was purchased from the American Type Culture Collection (ATCC, HTB-43, Wesel, Germany) and cultured in Dulbecco's Modified Eagle Medium, highglucose (DMEM, Sigma-Aldrich), supplemented with $10 \%$ heat-inactivated FBS, $100 \mathrm{U} / \mathrm{mL}$ penicillin and $100 \mu \mathrm{g} / \mathrm{mL}$ streptomycin. FaDu cells between passage 30 and 65 were used.

All cells were monthly screened for mycoplasma infections with the PlasmoTest ${ }^{\mathrm{TM}}$ kit (InvivoGen).

\section{Flow Cytometry}

The percentage of eGFP-positive DPSCs was first quantified by flow cytometric analysis. Hence, naïve and transduced DPSCs were rinsed twice in FACS buffer (2\% FBS in phosphate buffered saline (PBS, Lonza, Walkersville, MD, USA)) and analysed by the FACSCalibur equipped with CellQuest Pro Software (BD, Erembodegem, Belgium) for 5000 or 10,000 events.

\section{Immunofluorescence}

Protein expression of eGFP by transduced DPSCs was further analysed by immunofluorescent stainings. Cells were seeded on coverslips and fixed with $4 \%$ paraformaldehyde (PFA). Unspecific binding sites were blocked in serum-free Blocking Buffer (Dako, Heverlee, Belgium) for $20 \mathrm{~min}$ at room temperature, after permeabilization in $0.05 \%$ Triton (Sigma-Aldrich) in PBS during $30 \mathrm{~min}$ at $4{ }^{\circ} \mathrm{C}$. Primary polyclonal rabbit anti-GFP antibody $(0.5 \mu \mathrm{g} / \mathrm{mL}$, \#ab6556, Abcam, Cambridge, UK) was incubated overnight at $4{ }^{\circ} \mathrm{C}$. Alexa Fluor 555-labelled secondary antibody goat antirabbit $(4 \mu \mathrm{g} / \mathrm{mL}$, \#A21430, Thermo Fisher Scientific, Erembodegem, Belgium) was incubated for $30 \mathrm{~min}$ and nuclei were stained with 4',6-diamidino-2-phenylindole (DAPI, $0.1 \mu \mathrm{g} / \mathrm{mL}$, Thermo Fisher Scientific) during $10 \mathrm{~min}$ at room temperature in the dark. Negative control samples, omitted of primary antibody, were included. Coverslips were mounted by Fluoromount-G $\mathrm{G}^{\mathrm{TM}}$ (Thermo Fisher Scientific) and pictures were taken by the Leica DM4000 B Microscope (Leica Microsystems, Wetzlar, Germany) at a final magnification of $200 \times$ and $400 \times$.

\section{In Vivo HNSCC Mouse Model}

Eight-week-old female Hsd:Athymic Nude-Foxn $1^{\text {nu }}$ mice (Harlan Laboratories, Indianapolis, IN, USA) were subcutaneously inoculated with $1 \times 10^{6} \mathrm{FaDu}$ cells in both flanks at the level of the shoulder $(n=26)$. Tumour cells were resuspended in $50 \mu \mathrm{L}$ serum-free DMEM medium and $50 \mu \mathrm{L}$ growth factor-reduced Matrigel (Corning, Lasne, Belgium). After 10 days, $1 \times 10^{6}$ DPSCs in $50 \mu \mathrm{L}$ serum-free $\alpha$-MEM medium were directly injected into one tumour per mice, while $50 \mu \mathrm{L}$ serum-free medium was added to the contralateral control tumour. In a second study, animals received a single injection of $1 \times 10^{6} \mathrm{FaDu}$ cells in the right flank and were inoculated with $1 \times 10^{6}$ DPSCs by an intravenous, intraperitoneal, peritumoural $(n=3)$ or intratumoural injection $(n=8)$ after 10 days. Tumour growth, stem cell survival and biodistribution were monitored for 2-4 weeks until humane endpoints were reached. Mice were euthanized by cervical dislocation and tumours were dissected for qRT-PCR and (immuno)histology. 


\section{Tumour Growth Measurements}

The effect of DPSCs on HNSCC growth was studied by monitoring the tumour size after intratumoural stem cell injection. The tumour size was measured blindly twice a week by a calliper. Tumour volume $\left(\mathrm{mm}^{3}\right)$ was calculated by the formula $0.5 \times a^{2} \times b$, with $a$ and $b$ representing the width and length of the tumour in $\mathrm{mm}$, respectively [63].

\section{Bioluminescence Imaging (BLI)}

The survival and biodistribution of Fluc-expressing DPSCs were monitored noninvasively $24 \mathrm{~h}, 7$ days and 14 days after their injection by BLI. Mice were anesthetized with isoflurane ( $2 \%$ in $100 \%$ oxygen) at a flow rate of $2 \mathrm{~L} / \mathrm{min}$. D-luciferin (15 mg/mL in PBS, Promega, Leiden, The Netherlands) was intravenously injected at a dose of $126 \mathrm{mg} / \mathrm{kg}$ body weight. Consecutive frames were acquired using an IVIS Spectrum (PerkinElmer, Waltham, MA, USA) until the maximum signal intensity was achieved. Images were processed using the Living Image Software (PerkinElmer). Regions of interest (ROIs) were marked around the BLI signal and the total photon flux $(\mathrm{p} / \mathrm{s})$ within this area was quantified by Aura Imaging Software (Spectral Instruments Imaging, Tucson, AZ, USA).

\section{Quantitative Reverse Transcriptase Polymerase Chain Reaction (qRT-PCR)}

Tumour expression of angiogenic- and EMT-related genes was analysed in mice bearing two contralateral tumours by the StepOne Plus PCR system (Applied Biosystems, Carlsbad, CA, USA). Tumours were snap frozen and stored at $-80{ }^{\circ} \mathrm{C}$ until further processing. After shredding of the tissues, total RNA was extracted by the RNeasy Plus Mini Kit (Qiagen, Venlo, The Netherlands), following the manufacturer's instructions. The concentration and purity of the isolated RNA were measured by Nanodrop spectrophotometry (NanoDrop 2000, Thermo Fisher Scientific) at $260 \mathrm{~nm}$, $260 / 230 \mathrm{~nm}$ and $260 / 280 \mathrm{~nm}$ ratio, respectively. cDNA was generated from $500 \mathrm{ng}$ RNA template with the qScript cDNA SuperMix (Quanta Biosciences, Gaithersburg, MD, USA), according to the manufacturer's protocol. qPCR mixes contained $0.3 \mu \mathrm{L}$ forward and reverse primers $(10 \mu \mathrm{M}$, Eurogentec, Seraing, Belgium) (Table 1), $5 \mu$ L FAST Sybr Green Master Mix (Applied Biosystems) and $2 \mu \mathrm{L}$ cDNA ( $1 / 10$ diluted in RNase-free water) in a final reaction volume of $10 \mu \mathrm{L}$. The amplification protocol consisted of an initial denaturation step at $95^{\circ} \mathrm{C}$ during $20 \mathrm{~s}, 40$ cycli at $95^{\circ} \mathrm{C}$ for $3 \mathrm{~s}$ and $60{ }^{\circ} \mathrm{C}$ during $30 \mathrm{~s}$, followed by one cycle at $95^{\circ} \mathrm{C}$ during $15 \mathrm{~s}$ and a final elongation step of $60 \mathrm{~s}$ at $60^{\circ} \mathrm{C}$. The melting curve was analysed by a gradual increase in temperature to $95{ }^{\circ} \mathrm{C}\left(+0.3{ }^{\circ} \mathrm{C} / 15 \mathrm{~s}\right)$. Data were normalized to the endogenous expression of housekeeping genes human ribosomal protein L13a (RPL13a) and cyclophilin A (cyc A) and mouse yrosine 3-monooxygenase/tryptophan 5-monooxygenase activation protein zeta (Ywhaz) and hypoxanthine phosphoribosyltransferase 1 (HPRT1). A non-template control was included for every gene. Data were analysed with the StepOne Software 2.3 (Applied Biosystems).

\section{Histology and Immunohistochemistry}

Tumours were fixed in $4 \%$ PFA for $48 \mathrm{~h}$ at $4{ }^{\circ} \mathrm{C}$ and the presence of blood vessels and EMT was evaluated. Following antigen retrieval in 10\% citrate buffer (Dako), endogenous peroxidase activity was inhibited. In addition, aspecific binding sites were blocked in serum-free Blocking Buffer for $20 \mathrm{~min}$ at room temperature. Tissues were incubated with primary monoclonal antibodies rabbit anti-mouse/human CD146 (2.5 $\mu \mathrm{g} / \mathrm{mL}$, EPR3208, \#ab75769, Abcam), mouse anti-human alpha-smooth muscle actin $(\alpha$-SMA, ready-to-use, ASM-1, \#PA0943, Leica Biosystems, Diegem, Belgium) or mouse anti-human Snail-2 $(2 \mu \mathrm{g} / \mathrm{mL}, \mathrm{A}-7$, \#sc166,476, Santa Cruz, Heidelberg, Germany) for $1 \mathrm{~h}$, followed by secondary antibody horseradish peroxidase (HRP) labelled goat anti-rabbit (ready-to-use, \#K4002, Dako) or anti-mouse (0.5 mM, \#P0447, Dako) during $30 \mathrm{~min}$ at room temperature. Protein expression was visualized by 3,3'-Diaminobenzidine (DAB, Dako), according to the manufacturer's instructions. Nuclei were counterstained with Mayer's haematoxylin for $8 \mathrm{~min}$ at room temperature. Negative controls in which primary antibodies were omitted were included. Tumour morphology was evaluated by haematoxylin-eosin (H\&E) and Masson's trichrome stainings. The H\&E staining was performed by incubation of tumour sections with haematoxylin for $8 \mathrm{~min}$ and eosin during $3 \mathrm{~min}$ at room temperature. For the Masson's trichrome staining, tissues were stained with haematoxylin and Ponceau/Fuchsine for $10 \mathrm{~min}$ and $5 \mathrm{~min}$, respectively. This was followed by incubation with $1 \%$ phosphomolybdic acid, aniline blue and again 1\% phosphomolybdic acid during $5 \mathrm{~min}$ and finally $1 \%$ acetic acid for $2 \mathrm{~min}$. Tissue sections were rehydrated, enclosed with DPX mounting medium (Merck, Darmstadt, Germany) and scanned by the Mirax digital slide scanner or Axio Scan.Z1 (Carl Zeiss, Jena, Germany). The percentage of positive cells was quantified by Axiovision 4.6 Software (Carl Zeiss) or ImageJ Software (National Institutes of Health (NIH), Bethesda, MD, USA), respectively.

\section{Transwell Migration Assay}

The in vitro tumour homing capacity of DPSCs was studied by a Boyden chamber migration assay. $\mathrm{FaDu}$ cells were seeded at a density of 25,000 cells $/ \mathrm{cm}^{2}$ in a 24-well plate in their standard culture medium. After overnight adherence, cells were rinsed in PBS and $500 \mu \mathrm{L}$ serum-free $\alpha$-MEM medium 
Table 1 Overview of primers used for qRT-PCR

\begin{tabular}{llll}
\hline Gene & Gene accession number & & Primer sequence 5'-3' \\
\hline Mouse Cd31 & NM_001032378.2 & Forward & GAC-TCA-CGC-TGG-TGC-TCT-ATG-C \\
Mouse Vegf & NM_001025250.3 & Reverse & FCA-GTT-GCT-GCC-CAT-TCA-TCA \\
& & Forward & CTC-CAG-GGC-TTC-ATC-GTT-A \\
Human TWIST & NM_000474.4 & Reverse & CAT-AAG-GAG-AGC-AGA-AGT-CC \\
Human SNAIL2 & NM_003068.5 & Reverse & ACT-ATG-GTT-TTG-CAG-GCC-AGT-T \\
Human $\alpha$-SMA & & Forward & CTT-TTT-CTT-GCC-CTC-ACT-GC \\
Human RPL13a & Reverse & GCT-TCG-GAG-TGA-AGA-AAT-GC \\
Human Cyc A & NM_012423.4 & Forward & GCA-CCC-CTG-AAC-CCC-AAG-GC \\
& & Reverse & GCA-CGA-TGC-CAG-TTG-TGC-GT \\
Mouse Hprt1 & NM_021130.5 & Forward & AAG-TTG-AAG-TAC-CTG-GCT-TTC \\
& & Reverse & GCC-GTC-AAA-CAC-CTT-GAG-AC \\
Mouse Ywhaz & NM_013556.2 & Forward & AGA-CTG-AGT-GGT-TGG-ATG-GC \\
& & Reverse & TCG-AGT-TGT-CCA-CAG-TCA-GC \\
\hline
\end{tabular}

Q-SMA: alpha-smooth muscle actin; Cyc A: cyclophilin A; HPRT1: hypoxanthine phosphoribosyltransferase 1; RPL13a: ribosomal protein L13a; VEGF: vascular endothelial growth factor; Ywhaz: yrosine 3-monooxygenase/tryptophan 5-monooxygenase activation protein zeta.

was added. $24 \mathrm{~h}$ later, 50,000 or 100,000 DPSCs were seeded in 24-Transwell inserts (pore size $8.0 \mu \mathrm{m}$, Corning) in $300 \mu \mathrm{L}$ serum-free $\alpha$-MEM medium and placed in the wells containing tumour cells. Medium with or without $10 \%$ FBS in the bottom wells was used as positive and negative control, respectively. After $24 \mathrm{~h}$, DPSCs were fixed in $4 \%$ PFA and stained with $0.1 \%$ crystal violet (Sigma-Aldrich) in $70 \%$ ethanol. Non-migrated cells on the upper side of the insert were swept away by a cotton swab. Representative pictures of transmigrated DPSCs on the lower side were captured by a Nikon eclipse TS100 inverted microscope with Jenoptik ProgRes C3 camera (Jenoptik, Jena, Germany) at a final magnification of $100 \times$. Alternatively, migrated DPSCs were dissociated and stained with $1.67 \mathrm{mM}$ calcein acetoxymethyl esther (BD) in Non-Enzymatic Cell Dissociation Solution Buffer (Sigma-Aldrich). The resulting fluorescent signal was measured by a FLUOstar Omega plate reader (excitation: $485 \mathrm{~nm}$, emission: $520 \mathrm{~nm}$, BMG LABTECH, Ortenberg, Germany). The absolute number of transmigrated stem cells was quantified based on a standard curve.

\section{Statistical Analysis}

All quantitative data were expressed as mean \pm standard error of the mean (S.E.M.). Statistical analysis was performed with GraphPad Prism 8 software (Graphpad Software, La Jolla, CA, USA). After testing data normality by the D'Agostino and Pearson omnibus normality test, the Mann-Whitney U test was performed to compare two groups. Tumour growth over time was statistically analysed using the two-way ANOVA and Sidak's multiple comparisons test. For the comparison of multiple groups, the one-way ANOVA test combined with the Dunnett's multiple comparisons test was used. $P$ values below 0.05 were considered statistically significant.

\section{Results}

\section{In Vivo Survival of DPSCs in the Tumour Microenvironment}

In order to evaluate the therapeutic potential of DPSCs as carriers to specifically deliver anti-cancer treatment in the tumour region, we investigated stem cell survival and biodistribution over time using BLI after intratumoural stem cell injection (Fig. 1). Therefore, immune-deficient mice bearing two HNSCC xenografts were injected with control medium or Fluc- and eGFP-expressing DPSCs. Successful lentiviral transduction of DPSCs was confirmed by immunofluorescence and flow cytometry, in which $97.91 \pm 0.16 \%$ of the transduced DPSC population was eGFP positive (see Additional file 1). Following intratumoural injection in the mouse xenograft model, DPSCs were detectable in the tumours for two weeks, while no BLI signal could be measured 
a

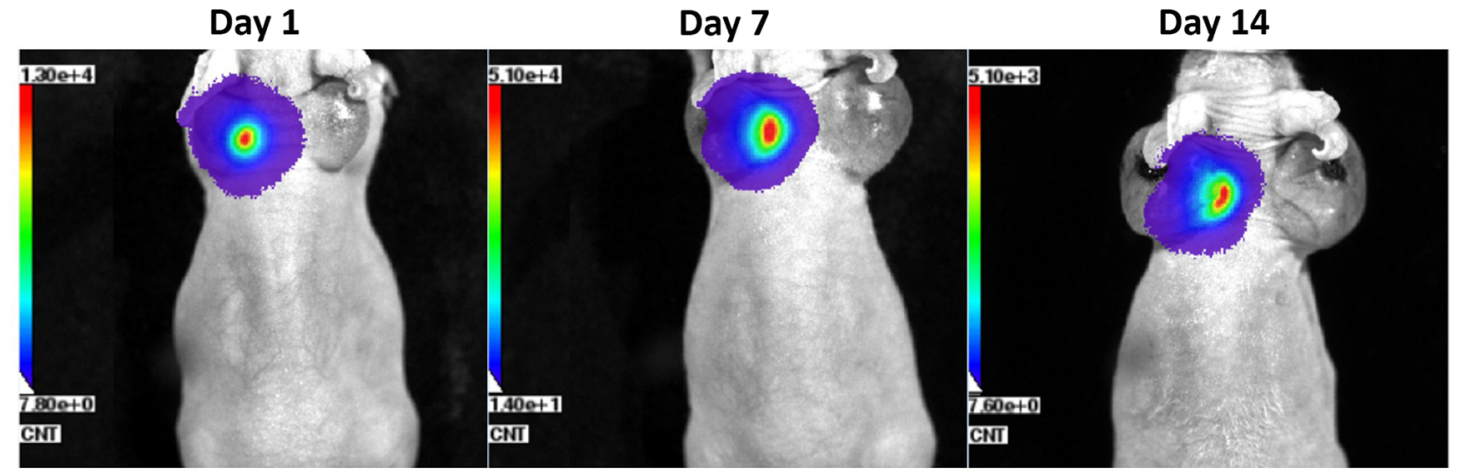

b

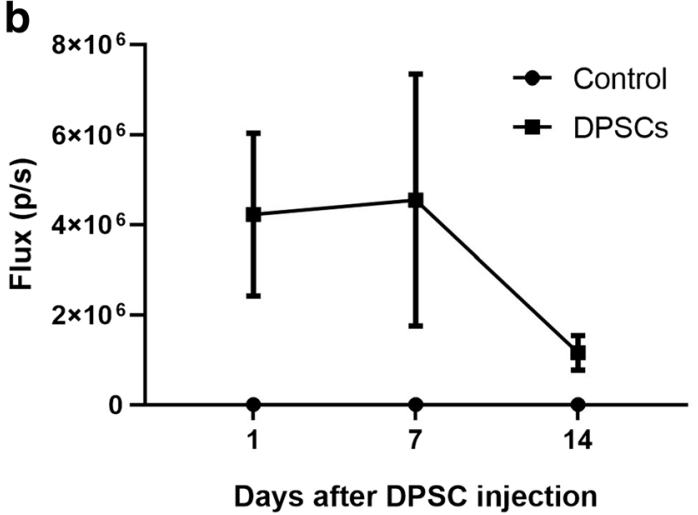

Fig. 1 Survival of DPSCs after their injection in HNSCC xenografts. $\mathrm{FaDu}$ tumour xenografts were induced in the contralateral flanks of mice. Ten days later, Fluc-expressing DPSCs or control medium was injected. Representative BLI pictures of DPSC presence are shown after

in the control tumours on the contralateral side (Fig. 1a). Quantification of the total photon flux showed a decrease in stem cell survival after 14 days to about $25 \%$, ranging from $4.2 \times 10^{6} \pm 1.8 \times 10^{6} \mathrm{p} / \mathrm{s}$ after $24 \mathrm{~h}$, to $4.6 \times 10^{6} \pm 2.8 \times 10^{6} \mathrm{p} / \mathrm{s}$ and $1.2 \times 10^{6} \pm 3.8 \times 10^{5} \mathrm{p} / \mathrm{s}$ after 7 and 14 days, respectively (Fig. 1b). These data suggest the survival and in situ persistence of intratumourally injected DPSCs in the applied HNC mouse model. In addition, no detectable BLI signal was noticed outside the original engraftment zone, indicating that stem cells have not migrated towards other tissues and organs.

\section{No Significant Effect of Transplanted DPSCs on the Morphology, Growth, EMT and Vascularization of Mouse HNSCC Grafts}

We evaluated whether DPSCs can be used safely as a cellbased tumour therapy. Therefore, the impact of DPSCs injected directly into the tumour on cancer aggressiveness was studied. First, tumour growth in mice bearing two contralateral tumours was followed-up over time. Although a tendency for faster growth was observed in DPSC-injected tumours, no significant difference in tumour volume could be measured during the first 14 days after stem cell transplantation $\left(561.35 \pm 98.74 \mathrm{~mm}^{3}\right.$
1, 7 and 14 days (a). Quantification of the total photon flux (p/s) in control and DPSC-injected tumours indicated the persistence of DPSCs in the xenografts, with a decline at day $14(\mathbf{b}, n=6)$. Data are expressed as mean \pm S.E.M.

(DPSCs) vs. $420.53 \pm 57.35 \mathrm{~mm}^{3}$ (control) at endpoint) (Fig. 2a). To exclude potential paracrine effects of transplanted DPSCs on the opposite control tumour, the same experiment was repeated in single tumour-bearing mice. Analogous results were observed on tumour growth for the first three weeks, with no significant effect of DPSC injection $\left(1108.42 \pm 164.61 \mathrm{~mm}^{3}\right.$ (DPSCs) vs. $872.31 \pm$ $82.94 \mathrm{~mm}^{3}$ (control) at endpoint) (Fig. 2b). H\&E stainings revealed a similar morphology for both DPSC- and noninjected HNC tumours, characterized by a heterogeneous appearance with high cellular density (Fig. 2c). In addition, tumour cells were embedded in a connective tissue-rich matrix as demonstrated by a Masson's trichrome staining (Fig. 2d).

In addition, the effect of DPSCs on tumour angiogenesis and EMT was tested after 14 days by measuring the gene and protein expression levels of process-related molecules (Figs. 3 and 4). Control and DPSC-injected tumours expressed similar levels of the vascular-related genes CD31 and vascular endothelial growth factor (VEGF) $(0.68 \pm 0.28$ (CD31) and $0.86 \pm$ 0.21 (VEGF)) (Fig. 3a). Furthermore, blood vessels were microscopically visualized in histological tumour sections by immunohistochemical staining for the endothelial marker CD146. Quantification of the percentage CD146-positive 
Fig. 2 No significant effect of DPSCs on HNSCC morphology and growth. $\mathrm{FaDu}$ xenografts were induced and injected with DPSCs or medium after 10 days. Mice received either two tumours (a, $n=20,4$ DPSC donors) or one tumour (b, $n=8,2$ DPSC donors). Tumour growth was measured over time, unveiling no significant influence of the injected DPSCs. Tumour volume $\left(\mathrm{mm}^{3}\right)$ is displayed as mean \pm S.E.M. and statistically analysed by two-way ANOVA and Sidak's multiple comparisons test (AB). The general morphology of the tumours from experiment A was compared by H\&E (c) or Masson's trichrome (d) staining at day 24 a

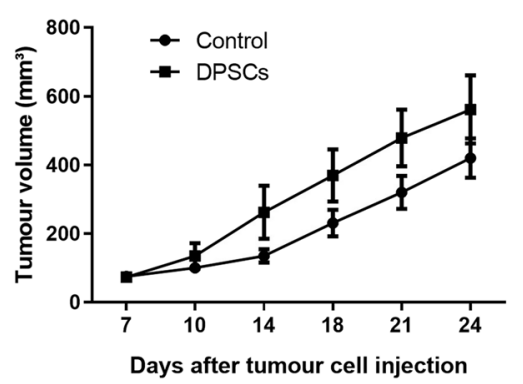

C

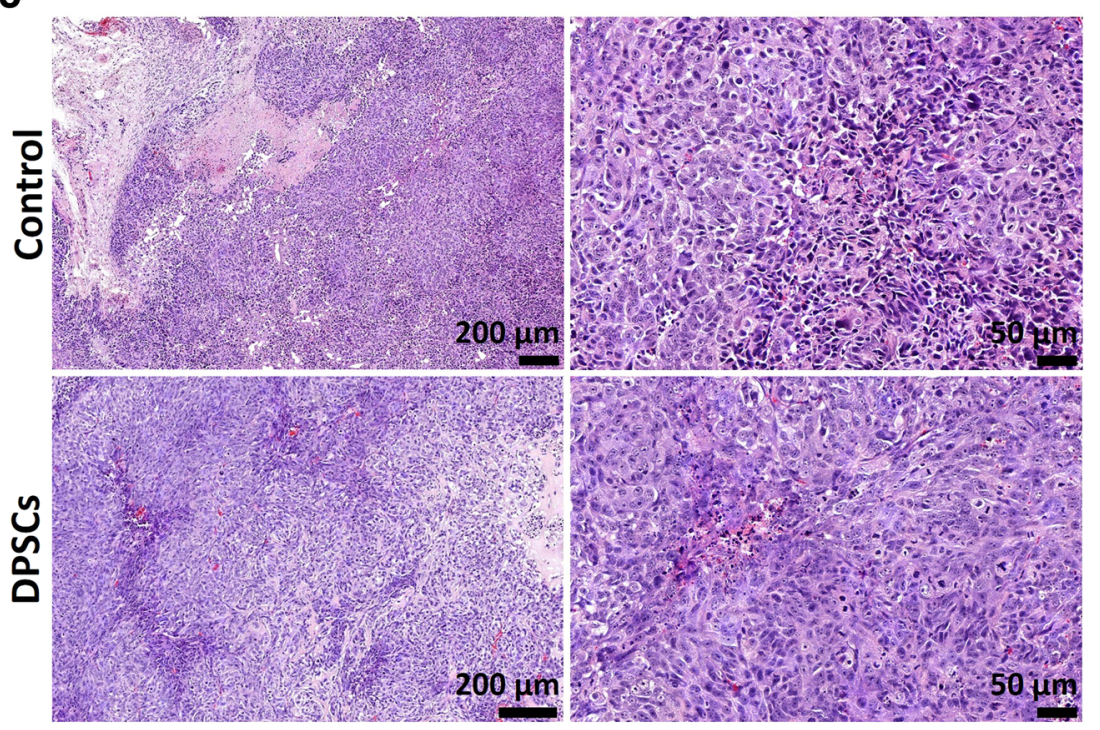

d

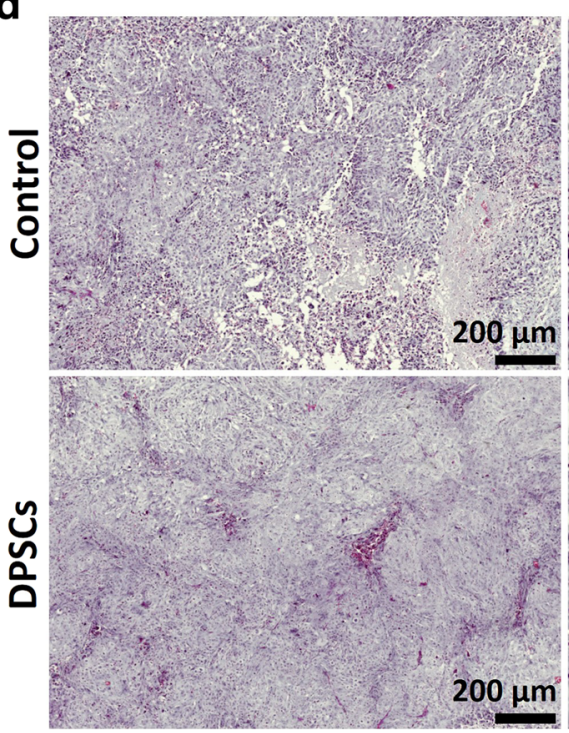

b
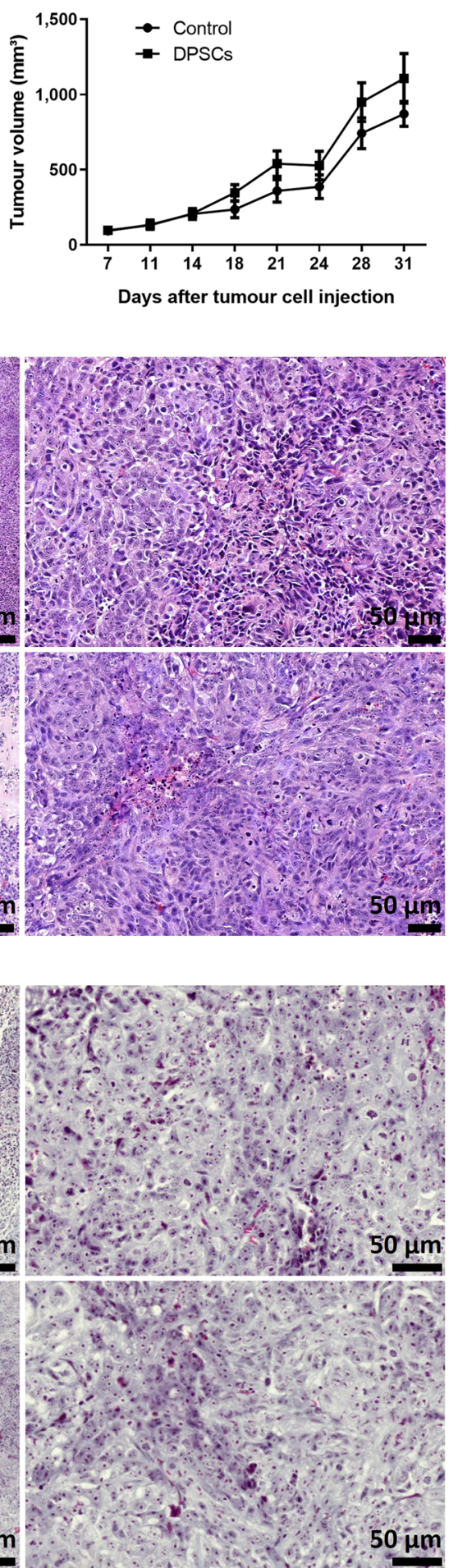

cells in the examined tissue area could not show a difference between both conditions ( $2.20 \pm 0.32 \%$ (DPSCs) vs. $2.21 \pm$ $0.69 \%$ (control)) (Fig. 3b).

Similar results were observed for the expression of EMT-supporting factors in HNSCC xenografts. Gene expression of TWIST, SNAIL2 and $\alpha$-SMA remained unchanged following the injection of DPSCs $(0.81 \pm$ 0.33 (TWIST), $0.95 \pm 0.40$ (SNAIL2), $0.66 \pm 0.12(\alpha-$ SMA)) (Fig. 4a). These findings were confirmed on the protein level for $\alpha$-SMA (Fig. 4b) and Snail-2 (Fig. 4c) by immunohistological stainings. Hence, no significant differences between control and DPSC- 
Fig. 3 DPSCs did not influence neovascularization in mouse HNSCC xenografts.

Vascularization of $\mathrm{FaDu}$ xenografts injected with DPSCs or medium (control) was evaluated by qRT-PCR for CD31 and VEGF after 24 days. Similar expression levels were measured for control and DPSC-injected tumours $(\mathbf{a}, n=5)$. The number of blood vessels was analysed by immunohistochemistry for CD146. Representative pictures of DPSC-injected or control xenografts show the presence of endothelial cells surrounding the blood vessels (indicated by arrows). Quantification of these cells in function of the total tissue area revealed no significant effect of DPSCs on tumour angiogenesis $(\mathbf{b}, \mathrm{n}=5)$. Data are presented as mean \pm S.E.M. and compared by the Mann-Whitney U test a
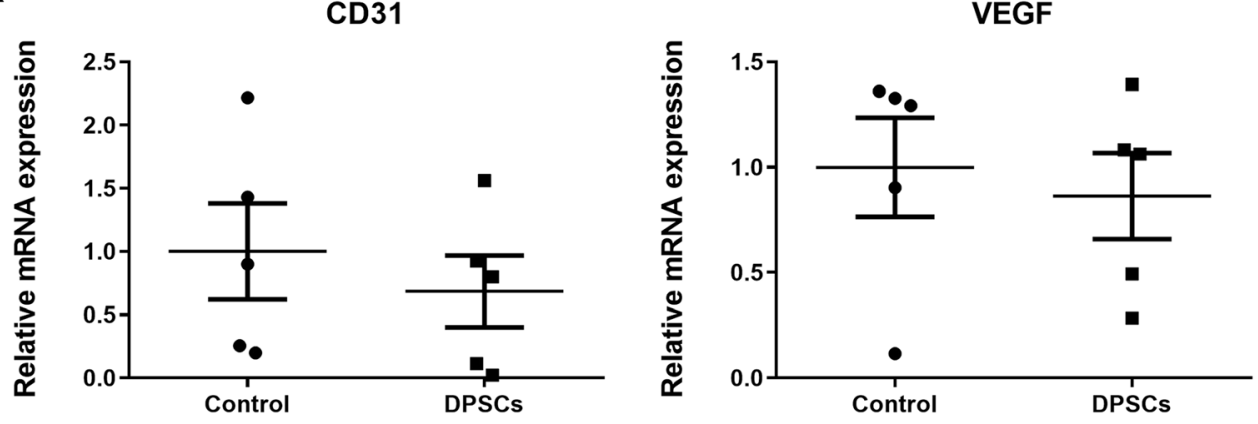

b
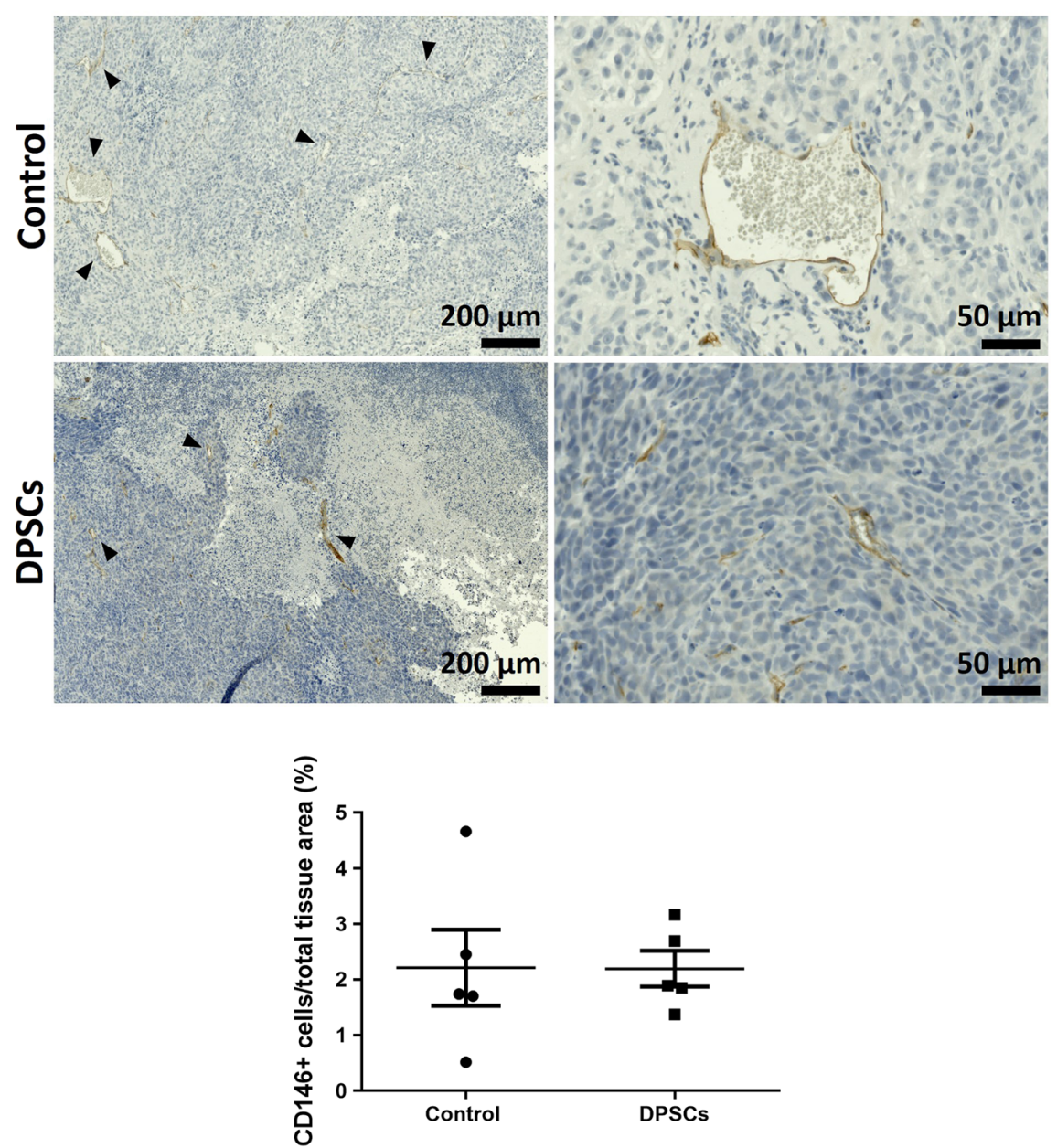

injected tumours could be observed ( $\alpha$-SMA: $0.18 \pm$ $0.06 \%$ (DPSCs) vs. $0.17 \pm 0.06 \%$ (control), Snail-2: $21.71 \pm 11.41 \%$ (DPSCs) vs. $25.53 \pm 11.87 \%$ (control)). While the Snail-2 protein was distributed throughout the tumour, $\alpha$-SMA expression was very limited and particularly concentrated in the smooth muscle cells around the blood vessels.

To conclude, DPSCs did not significantly influence tumour growth, morphology, neovascularization nor EMT in a mouse HNSCC xenograft model under the given conditions.

\section{In Vitro and In Vivo Tumour Homing Capacity of DPSCs}

The potential of DPSCs to specifically home towards HNSCC tumours was tested. The tumour tropism of DPSCs was first studied in an in vitro transwell migration assay (Fig. 5a). Significant stem cell migration towards the $\mathrm{FaDu}$ tumour cell line could be observed $(12,616 \pm 1694$ vs. $2501 \pm 661$ migrated cells) (Fig. 5b). Moreover, transduction of DPSCs with the Fluc-eGFP lentiviral vector had no effect on their tumour homing potency (data not shown). 
a

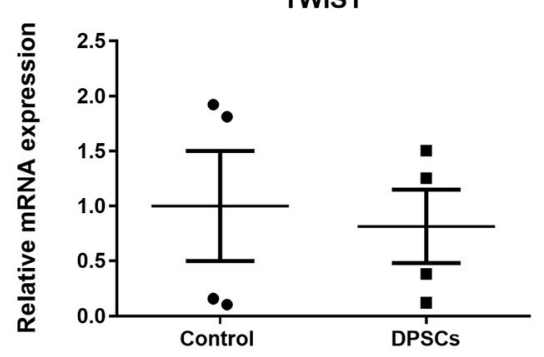

SNAIL2

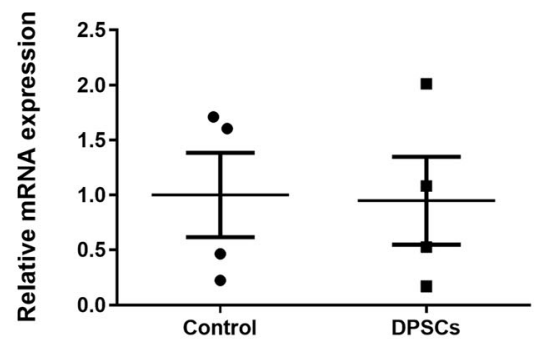

$\alpha-S M A$

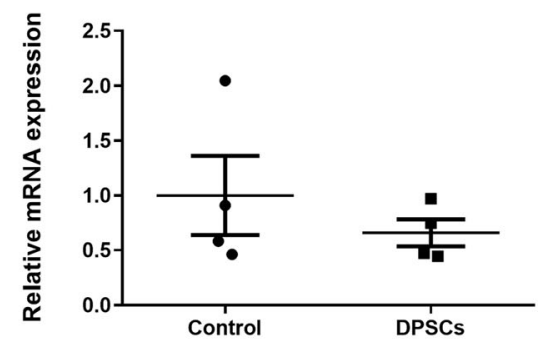

b
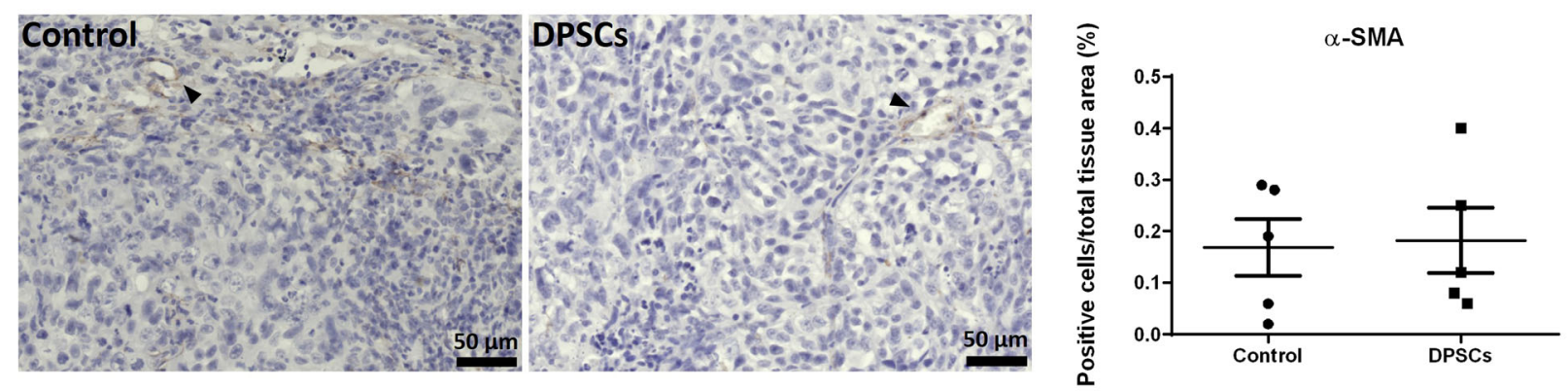

$\alpha-S M A$

C

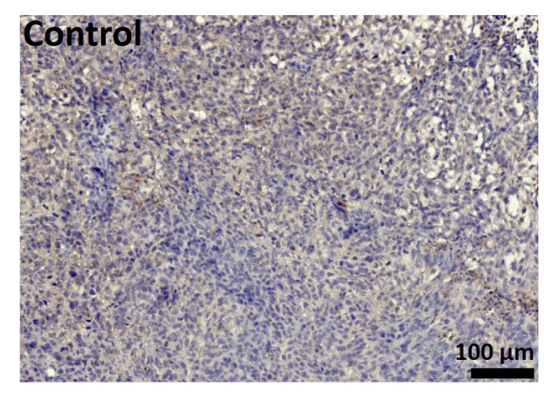

Fig. 4 DPSCs have no effect on EMT in HNSCC grafts. Expression levels of TWIST, SNAIL 2 and $\alpha$-SMA were measured in control and DPSC-injected $\mathrm{FaDu}$ xenografts. No differences in EMT-related gene expression were detected $(\mathbf{a}, n=4)$. Protein levels of $\alpha$-SMA (b) and
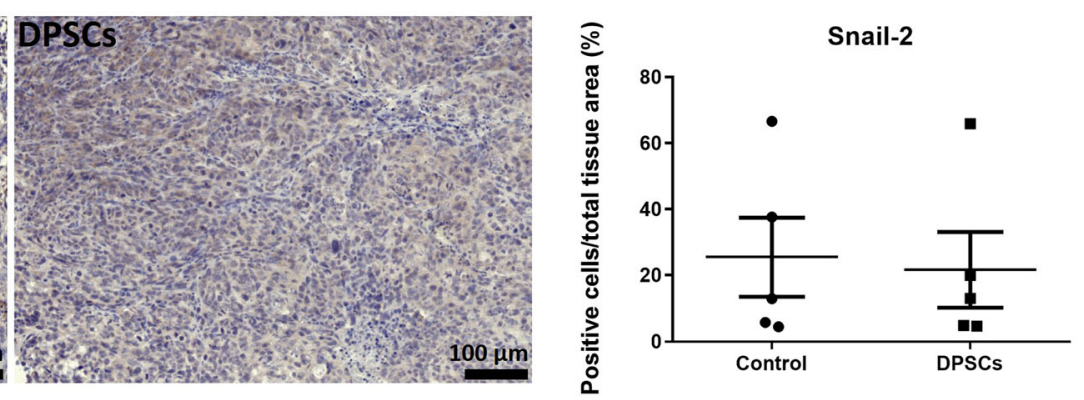

Snail-2

Snail-2 (c) were evaluated in tumour sections by immunohistochemistry. The percentage of positive cells was quantified, but was not changed in DPSC-injected tumours as analysed by the Mann-Whitney U test $(n=5)$. Data are mentioned as mean \pm S.E.M.

In order to study the in vivo tropism of DPSCs, Flucexpressing stem cells were injected intravenously, intraperitoneally or peritumourally in a $\mathrm{FaDu}$ xenograft mouse model. Cell biodistribution was followed-up during two weeks by BLI. Intravenously administered DPSCs were entrapped in the lungs of all animals after $24 \mathrm{~h}$, with the signal persisting for two weeks (Fig. 5c). After intraperitoneal injection, the detection of DPSCs was restricted to the abdominal cavity. In one out of three mice no BLI signal could be measured, suggesting an experimental error (Fig. 5d). Finally, peritumourally administered DPSCs persisted at the injection site mediocaudal of the tumour xenograft (Fig. 5e). In all conditions, the measured BLI signal gradually decreased over time, suggesting stem cell death. While the signal was already strongly decreased at day 7 after intravenous delivery, this decline was only observed after 14 days in the intraperitoneally and peritumourally injected mice.
To conclude, despite their in vitro migration potential towards a HNSCC cell line, a first pilot experiment in an immune-deficient HNSCC xenograft mouse model could not reveal in vivo homing of DPSCs following diverse administration routes.

\section{Discussion}

HNC remains one of the ten most common cancer types worldwide, associated with a high morbidity and mortality $[1,8]$. More efficient and targeted therapies are required to reduce this disease burden. Therefore, this study aimed to elucidate the potential safe use of DPSCs as therapeutic carriers to treat $\mathrm{HNC}$.

As a first objective, the biological behaviour of DPSCs directly injected in a mouse HNSCC xenograft model was 
a
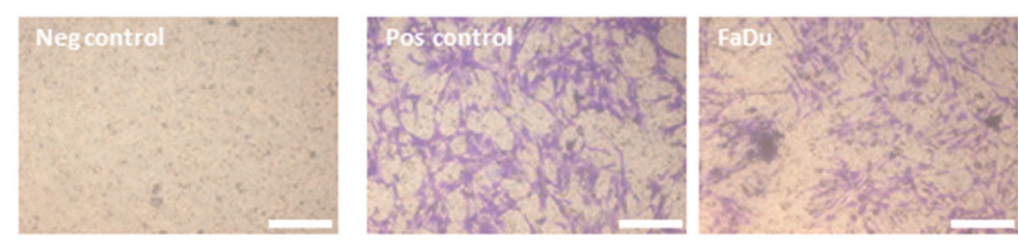

Day 7
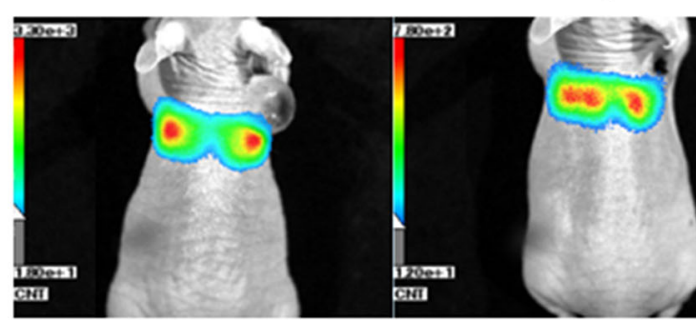

d
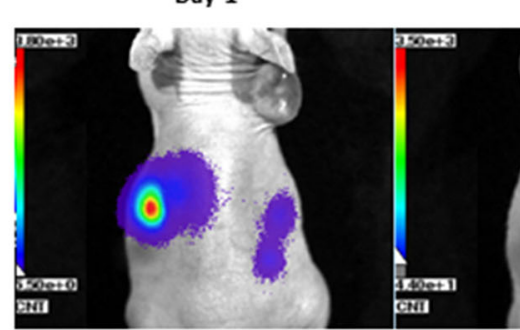

Day 7

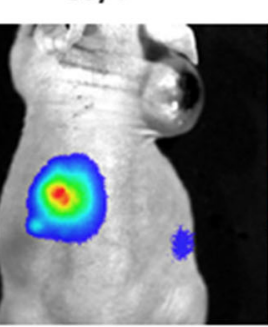

Day 1

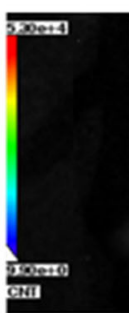

Day 7
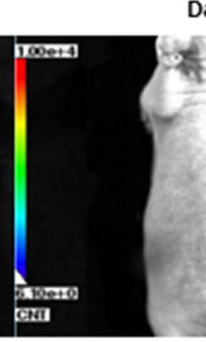

Day 14

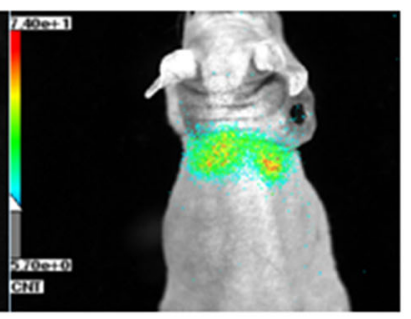

Day 14

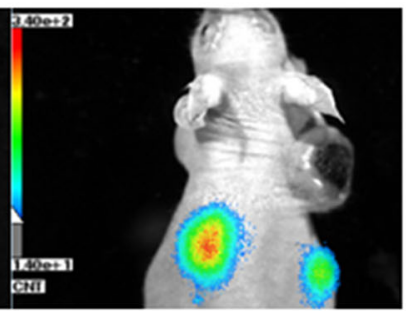

Day 14

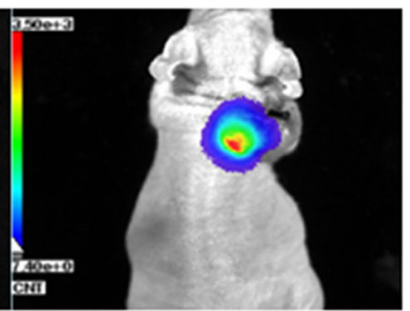

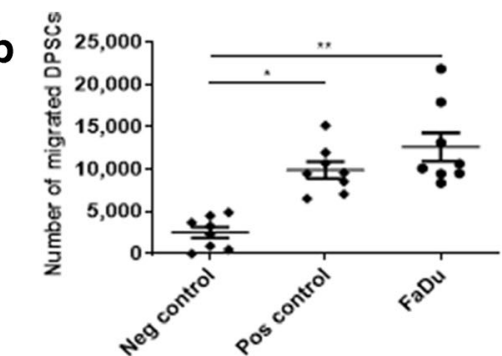

Intravenous injection

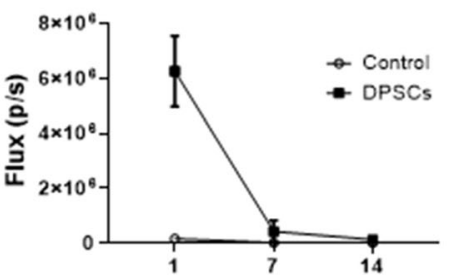

Days after DPSC injection

Intraperitoneal injection

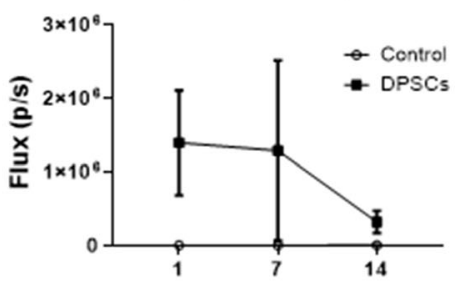

Days after DPSC injection Peritumoural injection

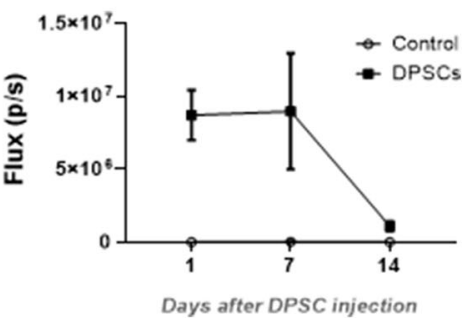

Fig. 5 DPSCs migrate towards HNSCC cells in vitro, which could not be confirmed in vivo. DPSC migration in vitro was assessed with the transwell assay. After $24 \mathrm{~h}$, DPSCs were able to migrate towards FaDu cells. Transmigrated DPSCs were visualized and quantified by crystal violet (a) and calcein $(\mathbf{b}, \mathrm{n}=8)$ staining, respectively. In addition, in vivo stem cell homing was assessed. DPSCs were injected intravenously (c), intraperitoneally (d) or peritumourally (e). DPSC survival and biodistribution were monitored over time using BLI. Injected DPSCs were detectable during 14 days, with a gradual decrease in signal intensity in time, but stem cell migration could not be observed $(n=3)$. Scale bars represent $200 \mu \mathrm{m}$ and quantitative data are expressed as mean \pm S.E.M. $* p<0.001, * * p<0.0001$ as determined by one-way ANOVA combined with Dunnett's multiple comparisons test evaluated. Stem cells were able to survive for at least two weeks in the tumour environment. After 14 days, their survival was decreased to about $25 \%$. Moreover, DPSCs did not have a significant effect on tumour growth and angiogenesis. Previous data of our research group and others indicated that DPSCs express a plethora of angiogenic factors, including VEGF, monocyte chemoattractant protein-1 (MCP-1) and plasminogen activator inhibitor-1 (PAI-1), and induce angiogenesis in vitro as well as in vivo [64, 65]. The lack of a significant effect of DPSCs themselves on blood vessel development in the tumour environment might be explained by the high intrinsic angiogenic capacity of tumour cells and HNSCC. In our settings, DPSCs had also no effect on EMT, which is a cellular mechanism associated with the loss of epithelial properties and the transformation towards a more migratory mesenchymal cell type by the reduction of cellcell contacts, which enhances tumour progression, invasion and metastasis $[26,66]$.

The number of previous studies on the safe use of DPSCs as HNC therapy is limited to Hanyu et al. Similar to our results, they did not observe significant effects of hDPSCderived $\mathrm{CM}$ on in vitro HNSCC proliferation and therapeutic 
sensitivity, and in vivo tumour growth, despite the increase in tumour VEGF secretion [67]. As mentioned before, for other MSC types both positive as well as negative effects on in vitro and in vivo $\mathrm{HNC}$ cell proliferation, survival, migration, invasion and therapeutic sensitivity have previously been described [68].

In addition, the in vitro and in vivo migration capacity of DPSCs towards the FaDu HNSCC cell line was evaluated. As previously demonstrated for BM-MSCs [69-72], FaDu cells displayed a significant chemoattractant effect on DPSCs in an in vitro transwell migration assay. Despite our positive in vitro transwell data, no migration of DPSCs towards FaDu tumours was observed over two weeks in an in vivo mouse tumour xenograft model after their intravenous, peritumoural or intraperitoneal administration. Intravenously injected DPSCs were mainly trapped in the small lung capillaries, which is a commonly described issue [73]. With a diameter of 15-16 $\mu \mathrm{m}$, DPSCs are slightly smaller than other MSC subtypes (17$18 \mu \mathrm{m})$ [55], but still outreach the size of the narrow lung capillary network $(6-15 \mu \mathrm{m})[74,75]$. Therefore, systemic administration of MSCs is generally not recommended in cancer and other scientific research fields, since the cell numbers reaching the desired target tissue are not sufficient to induce therapeutic effects [73, 76-78]. Nevertheless, gradual migration of entrapped MSCs towards tumours has been demonstrated by other researchers and systemic administration could be useful in case of lung tumours or metastases $[14,18,72$, 79]. Furthermore, it cannot be excluded that MSCs captured in the lungs might play a beneficial paracrine role on distant tumours [80]. After peritoneal injection, DPSCs persisted in the abdominal cavity where they could be attached to peritoneal surfaces, such as mesentery and omentum, or accumulated in spleen and lymph nodes which has been demonstrated for BM-MSCs [81]. Peritumourally administered stem cells also persisted in the injection site surrounding the tumour, with no migration being observed. Similarly, Zurmukhtashvili et al. studied the tropism of intravenously injected mouse BM-MSCs towards human oral squamous carcinoma cells. BLI revealed concentration of the stem cells in the lungs, with no signal detected at the tumour site [78]. In contrast, Zielske et al. did show specific in vivo tropism of intravenously injected hBMMSCs towards head and neck UMSCC1 xenografts, but the number of migrated cells was relatively low compared to HT29 colon and MDA-MB-231 breast carcinomas. Moreover, in comparison to the other tumour cell lines, MSC migration towards the head and neck tumours could not be stimulated by irradiation [79]. Wang et al. also showed the migration of hBMMSCs towards hypopharyngeal carcinoma after intravenous administration [72].

These conflicting data on the safety and homing of MSCs in the cancer research field could be related to MSC origin, tumour type and other experimental parameters that interfere with the MSC-tumour cross-talk. Tumours are considered chronic wounds, resulting in a strong immune response with the release of cytokines, chemokines and growth factors [82]. Therefore, tumour homing is suggested to be mediated by similar mechanisms underlying MSC tropism towards inflammatory or injury sites [83]. This hypothesis is supported by the stimulating effect on MSC migration following tumour destruction by irradiation $[84,85]$. The secretion profile of chemoattractant molecules and the resulting MSC homing vary depending on the tumour type, size, grade and inflammatory status $[78,86]$. Furthermore, the expression of associated chemokine receptors on MSCs depends on their tissue origin [45]. Hence, the immune status of the used experimental animal model might play an important role in the observed results on MSC homing and tumour aggressiveness. As reviewed by Oloyo et al., most researchers (64\%) utilize immune-competent animals. Sixty-one percent of these studies observed tumour-stimulatory effects, while this was only $48 \%$ in immune-deficient or immunocompromised animal models [87]. These data suggest a significant indirect interaction of MSCs with tumour cells via the immune system and notify the impact of the animal model on the observed results. Since our study was performed in athymic mice lacking $\mathrm{T}$ cell-mediated immune responses, further validation of our observations in immune-competent animals is essential to obtain a more significant reflection of the clinical situation .

Future research should focus on optimizing the in vivo tumour homing capacity of DPSCs in order to enable indirect stem cell delivery modes. Potential alternative administration routes include intra-arterial injection which circumvents the lung barrier and induced superior MSC homing in a glioma model compared to intravenous application [13]. Furthermore, the ratio of DPSCs to tumour cells could be reduced to increase the relative availability of tumoursecreted chemotactic factors per stem cell. Although MSC tumour homing is generally observed after a few hours to days, it cannot be excluded that DPSC migration towards HNSCC xenografts requires several weeks. However, due to the rapid growth of $\mathrm{FaDu}$ xenografts, longer follow-up of the animals was ethically not possible under the tested conditions of our experiment as humane endpoints had been reached. In order to prolong in vivo analysis of stem cell biodistribution, lower tumour cell numbers could be inoculated to slow down tumour growth and DPSCs could be injected in an earlier stage of tumour development or co-injected with tumour cells. In that case, the possible risk would be that the tumours could not produce a sustainable amount of chemokines to attract the DPSCs. Alternative approaches to enhance tumour homing could be the overexpression of important chemokine receptors (e.g., C-X-C motif chemokine receptor 4 (CXCR4)) on DPSCs or tumour irradiation which increases the release of chemoattractant molecules by tumour-associated cells.

Although the tumour-promoting or -suppressing effects and homing potential of MSCs remain controversial, 
preclinical studies show promising results for MSCs as vehicles for the continuous delivery of anti-cancer therapeutics. This hypothesis is also supported by our preliminary data on in vivo DPSC survival and safe interaction with tumour cells after their direct intratumoural application. Administration of MSCs genetically overexpressing tumour necrosis factor-related, apoptosis-inducing ligand (TRAIL), cytokines, angiogenic inhibitors or suicide genes reduced tumour cell viability and growth and improved survival rates in diverse animal cancer models [88-91]. Data on the in vivo therapeutic potential of DPSCs carrying anti-tumour drugs are currently scarce and requires further intensive research. A single study by Altanerova et al. suggested specific homing and tumoursuppressing effects for hDPSCs, genetically transduced with suicide genes and labelled by iron oxide, in a rat glioblastoma model. Nevertheless, reduction in tumour cell growth was solely demonstrated in vitro and the in vivo tropism was only based on the detection of iron oxide in the tumour region. It was not clear whether the DPSCs were still alive at that moment or that their iron oxide was taken up by other cells such as macrophages. Experiments to adequately confirm the presence of viable transplanted DPSCs were not performed [92].

\section{Conclusion}

To conclude, our data suggest the safe use of intratumourally applied DPSCs as therapeutic vehicles for the treatment of HNSCC. Nevertheless, since we could only monitor tumours for 14 days in immunocompromised mice, further long-term in vivo studies in an immune-competent mouse model are essential. In this respect, elucidating the effect of both cell types on each other's secretome (e.g. after long-term co-culture) would be highly valuable. In addition, optimization of the number and timing of DPSC injection might improve their tumour homing potential and requires further analysis. Comparative studies with other MSC subtypes should also reveal whether the strong proliferative and easily isolated DPSCs are the most efficient and safe MSCs for HNC treatment, since the bidirectional interaction between MSCs and tumour cells is strongly dependent on the tissue origin of both cell types, among many other experimental conditions.

\footnotetext{
Abbreviations $\alpha$-MEM, Minimum Essential Medium, alpha modification; $\alpha$-SMA, Alpha-smooth muscle actin; ATCC, American Type Culture Collection; AT-MSCs, Adipose tissue-derived mesenchymal stromal cells; BLI, Bioluminescence imaging; BM-MSCs, Bone marrow-derived mesenchymal stromal cells; CAFs, Cancer-associated fibroblasts; CM, Conditioned medium; CSCs, Cancer stem cells; CXCR, C-X-C motif chemokine receptor; Cyc A, Cyclophilin A; DAB, 3,3'-Diaminobenzidine; DAPI, 4',6-diamidino-2-phenylindole; DMEM, Dulbecco's Modified Eagle Medium; DPSCs, Dental pulp stromal cells; eGFP, Enhanced green fluorescent protein; EGFR, Epidermal growth factor receptor; EMT, Epithelial-to-mesenchymal transition;
}

EVs, Extracellular vesicles; FBS, Foetal bovine serum; Fluc, Firefly luciferase; GFP, Green fluorescent protein; H\&E, Haematoxylin-eosin; hBM-MSCs, Human bone marrow-derived mesenchymal stromal cells; hDPSCs, Human dental pulp stromal cells; HNC, Head and neck cancer; HNSCC, Head and neck squamous cell carcinoma; HPRT1, Hypoxanthine phosphoribosyltransferase 1; HPV, Human Papilloma Virus; IL, Interleukin; ISCT, International Society for Cellular Therapy; MCP-1, Monocyte chemoattractant protein-1; MMPs, Matrix metalloproteinases; MSCs, Mesenchymal stromal cells; PAI-1, Plasminogen activator inhibitor-1; PBS, Phosphate buffered saline; PFA, Paraformaldehyde; PI3K, Phosphoinositide-3-kinase; PTEN, Phosphatase and tensin homolog; (qRT-)PCR, (quantitative reverse transcriptase) Polymerase chain reaction; RB, Retinoblastoma; ROIs, Regions of interest; RPL13a, Ribosomal protein L13a; S.E.M., Standard error of the mean; TGF $\beta$, Transforming growth factor- $\beta$; TRAIL, Tumour necrosis factor-related, apoptosis-inducing ligand; UC-MSCs, Umbilical cord-derived mesenchymal stromal cells; VEGF, Vascular endothelial growth factor; WJ-MSCs, Wharton's Jelly-derived mesenchymal stromal cells; Ywhaz, Yrosine 3-monooxygenase/tryptophan 5-monooxygenase activation protein zeta; ZOL, Ziekenhuis OostLimburg

Supplementary Information The online version contains supplementary material available at https://doi.org/10.1007/s12015-021-10159-1.

Acknowledgements We would like to thank Evelyne Van Kerckhove and Jeanine Santermans for their excellent technical assistance.

Availability of Data and Materials The datasets used and/or analysed during the current study are available from the corresponding author on reasonable request.

Author's Contributions G.M. contributed to conception, experimental design, data collection and interpretation, statistical analyses and writing of the manuscript. M.L.M., E.W. and A.B. contributed to conception, experimental design, data collection and interpretation, statistical analyses and critical revision of the manuscript. I.L. and U.H. contributed to experimental design and critical revision of the manuscript. All authors gave their approval for the final manuscript and agree to be accountable for all aspects of the work.

Funding G.M. was supported by 'Bijzonder Onderzoeksfonds' of Hasselt University (BOF, BOF16DOC06). M.L.M. was funded by 'Bijzonder Onderzoeksfonds' and 'Fonds Spécial de Recherche' (BOF16DOCNA02-FSR-confin UHasselt-UNamur). This research was further supported by research grants to I.L., U.H., A.B. and E.W. from the Research Foundation Flanders ('Fonds Wetenschappelijk Onderzoek Vlaanderen (FWO)', grant numbers G0C1916FWO, $1517916 \mathrm{~N}$ and G0A7514N), BOF of Hasselt University (BOF20TT04), Limburg Cancer foundation ('Limburgs kankerfonds' LIKAF) and KU Leuven for PF 10/017 IMIR. The funding bodies played no role in study design, data collection, analysis and interpretation, or writing of the manuscript.

\section{Declarations}

Ethics Approval and Consent to Participate The study protocol on DPSC isolation was approved by the medical ethical committee of Hasselt University (Hasselt, Belgium, protocol 13/0104 U, date of approval 3 February 2014) and written informed consent was obtained from the donors or guardians in case of minors. The Ethical Committee on Animal Experiments of Hasselt University (Hasselt, Belgium) and KU Leuven (Leuven, Belgium) approved the in vivo experimental set-up of the tumour mouse model. 
Consent for Publication Not applicable.

Competing Interests The authors declare that they have no competing interests.

\section{References}

1. Bray, F., Ferlay, J., Soerjomataram, I., Siegel, R. L., Torre, L. A., \& Jemal, A. (2018). Global cancer statistics 2018: GLOBOCAN estimates of incidence and mortality worldwide for 36 cancers in 185 countries. CA: a Cancer Journal for Clinicians, 68(6), 394- 424.

2. Chow, L. Q. M. (2020). Head and neck Cancer. The New England Journal of Medicine, 382(1), 60-72.

3. Skarsgard, D. P., Groome, P. A., Mackillop, W. J., Zhou, S., Rothwell, D., Dixon, P. F., O'Sullivan, B., Hall, S. F., \& Holowaty, E. J. (2000). Cancers of the upper aerodigestive tract in Ontario, Canada, and the United States. Cancer., 88(7), 17281738.

4. Simard, E. P., Torre, L. A., \& Jemal, A. (2014). International trends in head and neck cancer incidence rates: Differences by country, sex and anatomic site. Oral Oncology, 50(5), 387-403.

5. Wyss, A., Hashibe, M., Chuang, S. C., Lee, Y. C., Zhang, Z. F., Yu, G. P., et al. (2013). Cigarette, cigar, and pipe smoking and the risk of head and neck cancers: Pooled analysis in the international head and neck Cancer epidemiology consortium. American Journal of Epidemiology, 178(5), 679-690.

6. Freedman, N. D., Schatzkin, A., Leitzmann, M. F., Hollenbeck, A. R., \& Abnet, C. C. (2007). Alcohol and head and neck cancer risk in a prospective study. British Journal of Cancer, 96(9), 1469-1474.

7. Michaud, D. S., Langevin, S. M., Eliot, M., Nelson, H. H., Pawlita, M., McClean, M. D., et al. (2014). High-risk HPV types and head and neck cancer. International Journal of Cancer, 135(7), 16531661.

8. Du, E., Mazul, A. L., Farquhar, D., Brennan, P., Anantharaman, D., Abedi-Ardekani, B., et al. (2019). Long-term survival in head and neck Cancer: Impact of site, stage, smoking, and human papillomavirus status. Laryngoscope., 129(11), 2506-2513.

9. Payakachat, N., Ounpraseuth, S., \& Suen, J. Y. (2013). Late complications and long-term quality of life for survivors ( $>5$ years) with history of head and neck cancer. Head \& Neck, 35(6), 819-825.

10. Andreasen, S., Kiss, K., Mikkelsen, L. H., Channir, H. I., Plaschke, C. C., Melchior, L. C., Eriksen, J. G., \& Wessel, I. (2019). An update on head and neck cancer: New entities and their histopathology, molecular background, treatment, and outcome. APMIS : acta pathologica, microbiologica, et immunologica Scandinavica., 127(5), 240-264.

11. Leemans, C. R., Braakhuis, B. J., \& Brakenhoff, R. H. (2011). The molecular biology of head and neck cancer. Nature reviews Cancer., 11(1), 9-22.

12. Bitsika, V., Roubelakis, M. G., Zagoura, D., Trohatou, O., Makridakis, M., Pappa, K. I., Marini, F. C., Vlahou, A., \& Anagnou, N. P. (2012). Human amniotic fluid-derived mesenchymal stem cells as therapeutic vehicles: A novel approach for the treatment of bladder cancer. Stem Cells and Development, 21(7), $1097-1111$

13. Doucette, T., Rao, G., Yang, Y., Gumin, J., Shinojima, N., Bekele, B. N., Qiao, W., Zhang, W., \& Lang, F. F. (2011). Mesenchymal stem cells display tumor-specific tropism in an RCAS/Ntv-a glioma model. Neoplasia., 13(8), 716-725.

14. Kidd, S., Spaeth, E., Dembinski, J. L., Dietrich, M., Watson, K., Klopp, A., Battula, V. L., Weil, M., Andreeff, M., \& Marini, F. C. (2009). Direct evidence of mesenchymal stem cell tropism for tumor and wounding microenvironments using in vivo bioluminescent imaging. Stem Cells, 27(10), 2614-2623.

15. McGrail, D. J., Ghosh, D., Quach, N. D., \& Dawson, M. R. (2012). Differential mechanical response of mesenchymal stem cells and fibroblasts to tumor-secreted soluble factors. PLoS One, 7(3), e33248.

16. Menon, L. G., Picinich, S., Koneru, R., Gao, H., Lin, S. Y., Koneru, M., Mayer-Kuckuk, P., Glod, J., \& Banerjee, D. (2007). Differential gene expression associated with migration of mesenchymal stem cells to conditioned medium from tumor cells or bone marrow cells. Stem Cells, 25(2), 520-528.

17. Vegh, I., Grau, M., Gracia, M., Grande, J., de la Torre, P., \& Flores, A. I. (2013). Decidua mesenchymal stem cells migrated toward mammary tumors in vitro and in vivo affecting tumor growth and tumor development. Cancer Gene Therapy, 20(1), 8-16.

18. Wang, H., Cao, F., De, A., Cao, Y., Contag, C., Gambhir, S. S., et al. (2009). Trafficking mesenchymal stem cell engraftment and differentiation in tumor-bearing mice by bioluminescence imaging. Stem Cells, 27(7), 1548-1558.

19. Melzer, C., Yang, Y., \& Hass, R. (2016). Interaction of MSC with tumor cells. Cell Communication and Signaling: CCS, 14(1), 20.

20. Lee, H. Y., \& Hong, I. S. (2017). Double-edged sword of mesenchymal stem cells: Cancer-promoting versus therapeutic potential. Cancer Science, 108(10), 1939-1946.

21. Ramasamy, R., Lam, E. W., Soeiro, I., Tisato, V., Bonnet, D., \& Dazzi, F. (2007). Mesenchymal stem cells inhibit proliferation and apoptosis of tumor cells: Impact on in vivo tumor growth. Leukemia., 21(2), 304-310.

22. Lin, J. T., Wang, J. Y., Chen, M. K., Chen, H. C., Chang, T. H., Su, B. W., \& Chang, P. J. (2013). Colon cancer mesenchymal stem cells modulate the tumorigenicity of colon cancer through interleukin 6. Experimental Cell Research, 319(14), 2216-2229.

23. Ljujic, B., Milovanovic, M., Volarevic, V., Murray, B., Bugarski, D., Przyborski, S., Arsenijevic, N., Lukic, M. L., \& Stojkovic, M. (2013). Human mesenchymal stem cells creating an immunosuppressive environment and promote breast cancer in mice. Scientific Reports, 3, 2298.

24. Nomoto-Kojima, N., Aoki, S., Uchihashi, K., Matsunobu, A., Koike, E., Ootani, A., Yonemitsu, N., Fujimoto, K., \& Toda, S. (2011). Interaction between adipose tissue stromal cells and gastric cancer cells in vitro. Cell and Tissue Research, 344(2), 287-298.

25. Vallabhaneni, K. C., Penfornis, P., Dhule, S., Guillonneau, F., Adams, K. V., Mo, Y. Y., Xu, R., Liu, Y., Watabe, K., Vemuri, M. C., \& Pochampally, R. (2015). Extracellular vesicles from bone marrow mesenchymal stem/stromal cells transport tumor regulatory microRNA, proteins, and metabolites. Oncotarget., 6(7), 49534967.

26. Xu, Q., Wang, L., Li, H., Han, Q., Li, J., Qu, X., et al. (2012). Mesenchymal stem cells play a potential role in regulating the establishment and maintenance of epithelial-mesenchymal transition in MCF7 human breast cancer cells by paracrine and induced autocrine TGF-beta. International Journal of Oncology, 41(3), 959968.

27. Zhu, W., Huang, L., Li, Y., Qian, H., Shan, X., Yan, Y., Mao, F., Wu, X., \& Xu, W. R. (2011). Mesenchymal stem cell-secreted soluble signaling molecules potentiate tumor growth. Cell Cycle, 10(18), 3198-3207.

28. Chao, K. C., Yang, H. T., \& Chen, M. W. (2012). Human umbilical cord mesenchymal stem cells suppress breast cancer tumourigenesis through direct cell-cell contact and internalization. Journal of Cellular and Molecular Medicine, 16(8), 1803-1815.

29. Ho, I. A., Toh, H. C., Ng, W. H., Teo, Y. L., Guo, C. M., Hui, K. M., et al. (2013). Human bone marrow-derived mesenchymal stem cells suppress human glioma growth through inhibition of angiogenesis. Stem Cells, 31(1), 146-155. 
30. Lu, Y. R., Yuan, Y., Wang, X. J., Wei, L. L., Chen, Y. N., Cong, C., Li, S. F., Long, D., Tan, W. D., Mao, Y. Q., Zhang, J., Li, Y. P., \& Cheng, J. Q. (2008). The growth inhibitory effect of mesenchymal stem cells on tumor cells in vitro and in vivo. Cancer Biology \& Therapy, 7(2), 245-251.

31. Sun, B., Roh, K. H., Park, J. R., Lee, S. R., Park, S. B., Jung, J. W., et al. (2009). Therapeutic potential of mesenchymal stromal cells in a mouse breast cancer metastasis model. Cytotherapy, 11(3), 289$2981 \mathrm{p}$ following 98.

32. Wang, M. L., Pan, C. M., Chiou, S. H., Chen, W. H., Chang, H. Y., Lee, O. K., et al. (2012). Oncostatin m modulates the mesenchymalepithelial transition of lung adenocarcinoma cells by a mesenchymal stem cell-mediated paracrine effect. Cancer Research, 72(22), 6051-6064.

33. Waterman, R. S., Henkle, S. L., \& Betancourt, A. M. (2012). Mesenchymal stem cell 1 (MSC1)-based therapy attenuates tumor growth whereas $\mathrm{MSC} 2$-treatment promotes tumor growth and metastasis. PLoS One, 7(9), e45590.

34. Rahmatizadeh, F., Gholizadeh-Ghaleh Aziz, S., Khodadadi, K., Lale Ataei, M., Ebrahimie, E., Soleimani Rad, J., \& Pashaiasl, M. (2019). Bidirectional and opposite effects of naive Mesenchymal stem cells on tumor growth and progression. Adv Pharm Bull., 9(4), 539-558.

35. Lim, Y. S., Lee, J. C., Lee, Y. S., Lee, B. J., \& Wang, S. G. (2012). Growth inhibitory effect of palatine tonsil-derived Mesenchymal stem cells on head and neck squamous cell carcinoma cells. Clin Exp Otorhinolaryngol., 5(2), 86-93.

36. Zhou, S., Cecere, R., \& Philip, A. (2017). CD109 released from human bone marrow mesenchymal stem cells attenuates TGF-betainduced epithelial to mesenchymal transition and stemness of squamous cell carcinoma. Oncotarget., 8(56), 95632-95647.

37. Liu, C., Feng, X., Wang, B., Wang, X., Wang, C., Yu, M., Cao, G., \& Wang, H. (2018). Bone marrow mesenchymal stem cells promote head and neck cancer progression through Periostin-mediated phosphoinositide 3-kinase/Akt/mammalian target of rapamycin. Cancer Science, 109(3), 688-698.

38. Scherzad, A., Steber, M., Gehrke, T., Rak, K., Froelich, K., Schendzielorz, P., et al. (2015). Human mesenchymal stem cells enhance cancer cell proliferation via IL-6 secretion and activation of ERK1/2. International Journal of Oncology, 47(1), 391-397.

39. Scherzed, A., Hackenberg, S., Radeloff, A., Froelich, K., Rak, K., Hagen, R., \& Kleinsasser, N. (2013). Human mesenchymal stem cells promote cancer motility and cytokine secretion in vitro. Cells, Tissues, Organs, 198(5), 327-337.

40. Wessely, A., Waltera, A., Reichert, T. E., Stock1, S., Grassel, S., \& Bauer, R. J. (2019). Induction of ALP and MMP9 activity facilitates invasive behavior in heterogeneous human BMSC and HNSCC 3D spheroids. The FASEB Journal, 33(11), 11884-11893.

41. de la Garza-Rodea, A. S., van der Velde-van Dijke, I., Boersma, H., Goncalves, M. A., van Bekkum, D. W., de Vries, A. A., et al. (2012). Myogenic properties of human mesenchymal stem cells derived from three different sources. Cell Transplantation, 21(1), 153-173.

42. Krampera, M., Marconi, S., Pasini, A., Galie, M., Rigotti, G., Mosna, F., et al. (2007). Induction of neural-like differentiation in human mesenchymal stem cells derived from bone marrow, fat, spleen and thymus. Bone., 40(2), 382-390.

43. Pirjali, T., Azarpira, N., Ayatollahi, M., Aghdaie, M. H., Geramizadeh, B., \& Talai, T. (2013). Isolation and characterization of human Mesenchymal stem cells derived from human umbilical cord Wharton's jelly and amniotic membrane. Int J Organ Transplant Med., 4(3), 111-116.

44. Gronthos, S., Mankani, M., Brahim, J., Robey, P. G., \& Shi, S. (2000). Postnatal human dental pulp stem cells (DPSCs) in vitro and in vivo. Proceedings of the National Academy of Sciences of the United States of America, 97(25), 13625-13630.
45. Belmar-Lopez, C., Mendoza, G., Oberg, D., Burnet, J., Simon, C., Cervello, I., Iglesias, M., Ramirez, J. C., Lopez-Larrubia, P., Quintanilla, M., \& Martin-Duque, P. (2013). Tissue-derived mesenchymal stromal cells used as vehicles for anti-tumor therapy exert different in vivo effects on migration capacity and tumor growth. BMC Medicine, 11, 139.

46. Sasso, R. C., LeHuec, J. C., \& Shaffrey, C. (2005). Spine Interbody Research G. Iliac crest bone graft donor site pain after anterior lumbar interbody fusion: a prospective patient satisfaction outcome assessment. J Spinal Disord Tech, 18(Suppl), S77-S81.

47. Alge, D. L., Zhou, D., Adams, L. L., Wyss, B. K., Shadday, M. D., Woods, E. J., Gabriel Chu, T. M., \& Goebel, W. S. (2010). Donormatched comparison of dental pulp stem cells and bone marrowderived mesenchymal stem cells in a rat model. Journal of Tissue Engineering and Regenerative Medicine, 4(1), 73-81.

48. Karaoz, E., Demircan, P. C., Saglam, O., Aksoy, A., Kaymaz, F., \& Duruksu, G. (2011). Human dental pulp stem cells demonstrate better neural and epithelial stem cell properties than bone marrowderived mesenchymal stem cells. Histochemistry and Cell Biology, 136(4), 455-473.

49. Gervois, P., Struys, T., Hilkens, P., Bronckaers, A., Ratajczak, J., Politis, C., Brône, B., Lambrichts, I., \& Martens, W. (2015). Neurogenic maturation of human dental pulp stem cells following neurosphere generation induces morphological and electrophysiological characteristics of functional neurons. Stem Cells and Development, 24(3), 296-311.

50. Zou, T., Jiang, S., Dissanayaka, W. L., Heng, B. C., Xu, J., Gong, T., Huang, X., \& Zhang, C. (2019). Sema4D/PlexinB1 promotes endothelial differentiation of dental pulp stem cells via activation of AKT and ERK1/2 signaling. Journal of Cellular Biochemistry, 120(8), 13614-13624.

51. Luzuriaga, J., Pastor-Alonso, O., Encinas, J. M., Unda, F., Ibarretxe, G., \& Pineda, J. R. (2019). Human dental pulp stem cells grown in neurogenic media differentiate into endothelial cells and promote Neovasculogenesis in the mouse brain. Frontiers in Physiology, 10, 347.

52. Martens, W., Sanen, K., Georgiou, M., Struys, T., Bronckaers, A., Ameloot, M., Phillips, J., \& Lambrichts, I. (2014). Human dental pulp stem cells can differentiate into Schwann cells and promote and guide neurite outgrowth in an aligned tissue-engineered collagen construct in vitro. The FASEB Journal, 28(4), 1634-1643.

53. Ratajczak, J., Bronckaers, A., Dillen, Y., Gervois, P., Vangansewinkel, T., Driesen, R. B., et al. (2016). The neurovascular properties of dental stem cells and their importance in dental tissue engineering. Stem Cells International., 2016, 9762871.

54. Gandia, C., Armiñan, A., García-Verdugo, J. M., Lledó, E., Ruiz, A., Miñana, M. D., Sanchez-Torrijos, J., Payá, R., Mirabet, V., Carbonell-Uberos, F., Llop, M., Montero, J. A., \& Sepúlveda, P. (2008). Human dental pulp stem cells improve left ventricular function, induce angiogenesis, and reduce infarct size in rats with acute myocardial infarction. Stem Cells, 26(3), 638-645.

55. Lan, X., Sun, Z., Chu, C., Boltze, J., \& Li, S. (2019). Dental pulp stem cells: An attractive alternative for cell therapy in ischemic stroke. Frontiers in Neurology, 10, 824.

56. Leong, W. K., Henshall, T. L., Arthur, A., Kremer, K. L., Lewis, M. D., Helps, S. C., Field, J., Hamilton-Bruce, M. A., Warming, S., Manavis, J., Vink, R., Gronthos, S., \& Koblar, S. A. (2012). Human adult dental pulp stem cells enhance poststroke functional recovery through non-neural replacement mechanisms. Stem cells translational medicine., 1(3), 177-187.

57. Ullah, I., Park, J. M., Kang, Y. H., Byun, J. H., Kim, D. G., Kim, J. H., Kang, D. H., Rho, G. J., \& Park, B. W. (2017). Transplantation of human dental pulp-derived stem cells or differentiated neuronal cells from human dental pulp-derived stem cells identically 
enhances regeneration of the injured peripheral nerve. Stem Cells and Development, 26(17), 1247-1257.

58. Lee, S., Zhang, Q. Z., Karabucak, B., \& Le, A. D. (2016). DPSCs from inflamed pulp modulate macrophage function via the TNF- $\alpha /$ IDO Axis. Journal of Dental Research., 95(11), 1274-1281.

59. Yamaza, T., Kentaro, A., Chen, C., Liu, Y., Shi, Y., Gronthos, S., Wang, S., \& Shi, S. (2010). Immunomodulatory properties of stem cells from human exfoliated deciduous teeth. Stem Cell Research \& Therapy, $1(1), 5$.

60. Hilkens, P., Gervois, P., Fanton, Y., Vanormelingen, J., Martens, W., Struys, T., Politis, C., Lambrichts, I., \& Bronckaers, A. (2013). Effect of isolation methodology on stem cell properties and multilineage differentiation potential of human dental pulp stem cells. Cell and Tissue Research, 353(1), 65-78.

61. Dominici, M., Le Blanc, K., Mueller, I., Slaper-Cortenbach, I., Marini, F., Krause, D., et al. (2006). Minimal criteria for defining multipotent mesenchymal stromal cells. The International Society for Cellular Therapy position statement. Cytotherapy., 8(4), 315317.

62. Struys, T., Ketkar-Atre, A., Gervois, P., Leten, C., Hilkens, P., Martens, W., Bronckaers, A., Dresselaers, T., Politis, C., Lambrichts, I., \& Himmelreich, U. (2013). Magnetic resonance imaging of human dental pulp stem cells in vitro and in vivo. Cell Transplantation, 22(10), 1813-1829.

63. Liekens, S., Bronckaers, A., Belleri, M., Bugatti, A., Sienaert, R., Ribatti, D., Nico, B., Gigante, A., Casanova, E., Opdenakker, G., Pérez-Pérez, M. J., Balzarini, J., \& Presta, M. (2012). The thymidine phosphorylase inhibitor 5'-O-tritylinosine (KIN59) is an antiangiogenic multitarget fibroblast growth factor-2 antagonist. Molecular Cancer Therapeutics, 11(4), 817-829.

64. Bronckaers, A., Hilkens, P., Fanton, Y., Struys, T., Gervois, P., Politis, C., Martens, W., \& Lambrichts, I. (2013). Angiogenic properties of human dental pulp stem cells. PLoS One, 8(8), e71104.

65. Hilkens, P., Fanton, Y., Martens, W., Gervois, P., Struys, T., Politis, C., Lambrichts, I., \& Bronckaers, A. (2014). Pro-angiogenic impact of dental stem cells in vitro and in vivo. Stem Cell Research, 12(3), 778-790.

66. Dittmer, A., Hohlfeld, K., Lutzkendorf, J., Muller, L. P., \& Dittmer, J. (2009). Human mesenchymal stem cells induce E-cadherin degradation in breast carcinoma spheroids by activating ADAM10. Cellular and Molecular Life Sciences, 66(18), 3053-3065.

67. Hanyu, S., Sakuma, K., \& Tanaka, A. (2019). A study on the effect of human dental pulp stem cell conditioned medium on human Oral squamous cell carcinoma cell lines. Journal of Hard Tissue Biology., 28(3), 281-288.

68. Papaccio, F., Paino, F., Regad, T., Papaccio, G., Desiderio, V., \& Tirino, V. (2017). Concise review: Cancer cells, Cancer stem cells, and Mesenchymal stem cells: Influence in Cancer development. Stem Cells Translational Medicine, 6(12), 2115-2125.

69. Al-toub, M., Almusa, A., Almajed, M., Al-Nbaheen, M., Kassem, M., Aldahmash, A., et al. (2013). Pleiotropic effects of cancer cells' secreted factors on human stromal (mesenchymal) stem cells. Stem Cell Research \& Therapy, 4(5), 114.

70. Scherzed, A., Hackenberg, S., Froelich, K., Kessler, M., Koehler, C., Hagen, R., Radeloff, A., Friehs, G., \& Kleinsasser, N. (2011). BMSC enhance the survival of paclitaxel treated squamous cell carcinoma cells in vitro. Cancer Biology \& Therapy, 11(3), 349357.

71. Scherzed, A., Hackenberg, S., Froelich, K., Rak, K., Schendzielorz, P., Gehrke, T., et al. (2016). The differentiation of hMSCs counteracts their migration capability and pro-angiogenic effects in vitro. Oncology Reports, 35(1), 219-226.

72. Wang, J., Zhu, L., Chen, X., Huang, R., Wang, S., \& Dong, P. (2019). Human bone marrow Mesenchymal stem cells functionalized by hybrid Baculovirus-Adeno-associated viral vectors for targeting Hypopharyngeal carcinoma. Stem Cells and Development, 28(8), 543-553.

73. Barbash, I. M., Chouraqui, P., Baron, J., Feinberg, M. S., Etzion, S., Tessone, A., Miller, L., Guetta, E., Zipori, D., Kedes, L. H., Kloner, R. A., \& Leor, J. (2003). Systemic delivery of bone marrow-derived mesenchymal stem cells to the infarcted myocardium: Feasibility, cell migration, and body distribution. Circulation., 108(7), 863868.

74. Doerschuk, C. M., Beyers, N., Coxson, H. O., Wiggs, B., \& Hogg, J. C. (1985). Comparison of neutrophil and capillary diameters and their relation to neutrophil sequestration in the lung. J Appl Physiol, 1993;74(6), 3040-3045.

75. Schrepfer, S., Deuse, T., Reichenspurner, H., Fischbein, M. P., Robbins, R. C., \& Pelletier, M. P. (2007). Stem cell transplantation: The lung barrier. Transplantation Proceedings, 39(2), 573-576.

76. Bianchi, G., Morandi, F., Cilli, M., Daga, A., Bocelli-Tyndall, C., Gambini, C., Pistoia, V., \& Raffaghello, L. (2012). Close interactions between mesenchymal stem cells and neuroblastoma cell lines lead to tumor growth inhibition. PLoS One, 7(10), e48654.

77. Fischer, U. M., Harting, M. T., Jimenez, F., Monzon-Posadas, W. O., Xue, H., Savitz, S. I., Laine, G. A., \& Cox Jr., C. S. (2009). Pulmonary passage is a major obstacle for intravenous stem cell delivery: The pulmonary first-pass effect. Stem Cells and Development, 18(5), 683-692.

78. Zurmukhtashvili, M., Machavariani, A., Dugashvili, G., Grdzelidze, T., Gogilashvili, K., Menabde, G., Abiatari, I., \& Marks, L. (2020). Mesenchymal stem cell transplantation attenuates growth of chemotherapy treated oral squamous cell carcinoma in an animal model. Journal of Oral Pathology \& Medicine, 49, 655-664.

79. Zielske, S. P., Livant, D. L., \& Lawrence, T. S. (2009). Radiation increases invasion of gene-modified mesenchymal stem cells into tumors. International Journal of Radiation Oncology, Biology, Physics, 75(3), 843-853.

80. Lee, R. H., Pulin, A. A., Seo, M. J., Kota, D. J., Ylostalo, J., Larson, B. L., Semprun-Prieto, L., Delafontaine, P., \& Prockop, D. J. (2009). Intravenous hMSCs improve myocardial infarction in mice because cells embolized in lung are activated to secrete the antiinflammatory protein TSG-6. Cell Stem Cell, 5(1), 54-63.

81. Bazhanov, N., Ylostalo, J. H., Bartosh, T. J., Tiblow, A., Mohammadipoor, A., Foskett, A., \& Prockop, D. J. (2016). Intraperitoneally infused human mesenchymal stem cells form aggregates with mouse immune cells and attach to peritoneal organs. Stem Cell Research \& Therapy, 7, 27.

82. Dvorak, H. F. (1986). Tumors: Wounds that do not heal. Similarities between tumor stroma generation and wound healing. The New England Journal of Medicine, 315(26), 1650-1659.

83. Spaeth, E., Klopp, A., Dembinski, J., Andreeff, M., \& Marini, F. (2008). Inflammation and tumor microenvironments: Defining the migratory itinerary of mesenchymal stem cells. Gene Therapy, 15(10), 730-738

84. Kim, S. M., Oh, J. H., Park, S. A., Ryu, C. H., Lim, J. Y., Kim, D. S., Chang, J. W., Oh, W., \& Jeun, S. S. (2010). Irradiation enhances the tumor tropism and therapeutic potential of tumor necrosis factor-related apoptosis-inducing ligand-secreting human umbilical cord blood-derived mesenchymal stem cells in glioma therapy. Stem Cells, 28(12), 2217-2228.

85. Klopp, A. H., Spaeth, E. L., Dembinski, J. L., Woodward, W. A., Munshi, A., Meyn, R. E., Cox, J. D., Andreeff, M., \& Marini, F. C. (2007). Tumor irradiation increases the recruitment of circulating mesenchymal stem cells into the tumor microenvironment. Cancer Research, 67(24), 11687-11695.

86. Schweizer, M. T., Wang, H., Bivalacqua, T. J., Partin, A. W., Lim, S. J., Chapman, C., Abdallah, R., Levy, O., Bhowmick, N. A., Karp, J. M., de Marzo, A., Isaacs, J. T., Brennen, W. N., \& Denmeade, S. R. (2019). A phase I study to assess the safety and 
Cancer-homing ability of allogeneic bone marrow-derived Mesenchymal stem cells in men with localized prostate Cancer. Stem Cells Translational Medicine, 8(5), 441-449.

87. Oloyo, A. K., Ambele, M. A., \& Pepper, M. S. (2018). Contrasting views on the role of Mesenchymal stromal/stem cells in tumour growth: A systematic review of experimental design. Advances in Experimental Medicine and Biology, 1083, 103-124.

88. Duhrsen, L., Hartfuss, S., Hirsch, D., Geiger, S., Maire, C. L., Sedlacik, J., et al. (2019). Preclinical analysis of human mesenchymal stem cells: Tumor tropism and therapeutic efficiency of local HSV-TK suicide gene therapy in glioblastoma. Oncotarget., 10(58), 6049-6061.

89. Grisendi, G., Bussolari, R., Cafarelli, L., Petak, I., Rasini, V., Veronesi, E., de Santis, G., Spano, C., Tagliazzucchi, M., BartiJuhasz, H., Scarabelli, L., Bambi, F., Frassoldati, A., Rossi, G., Casali, C., Morandi, U., Horwitz, E. M., Paolucci, P., Conte, P. F., \& Dominici, M. (2010). Adipose-derived mesenchymal stem cells as stable source of tumor necrosis factor-related apoptosisinducing ligand delivery for cancer therapy. Cancer Research, 70(9), 3718-3729.
90. Zhang, D., Zheng, L., Shi, H., Chen, X., Wan, Y., Zhang, H., Li, M., Lu, L., Luo, S., Yin, T., Lin, H., He, S., Luo, Y., \& Yang, L. (2014). Suppression of peritoneal tumorigenesis by placentaderived mesenchymal stem cells expressing endostatin on colorectal cancer. International Journal of Medical Sciences, 11(9), 870 879.

91. Zhang, X., Xu, W., Qian, H., Zhu, W., \& Zhang, R. (2011). Mesenchymal stem cells modified to express lentivirus TNFalpha Tumstatin(45-132) inhibit the growth of prostate cancer. Journal of Cellular and Molecular Medicine, 15(2), 433-444.

92. Altanerova, U., Benejova, K., Altanerova, V., Tyciakova, S., Rychly, B., Szomolanyi, P., et al. (2016). Dental pulp mesenchymal stem/stromal cells labeled with iron sucrose release exosomes and cells applied intra-nasally migrate to intracerebral glioblastoma. Neoplasma., 63(6), 925-933.

Publisher's Note Springer Nature remains neutral with regard to jurisdictional claims in published maps and institutional affiliations. 